\title{
LA EDUCACIÓN CÍVICO-TRIBUTARIA: \\ UNA ASIGNATURA PENDIENTE Y UN INSTRUMENTO NECESARIO CONTRA EL FRAUDE FISCAL*
}

\author{
Sergio Siverio Luis \\ Profesor ayudante de Derecho Constitucional \\ Universidad de La Laguna
}

\section{RESUMEN}

La educación cívico-tributaria es un instrumento imprescindible para combatir el fraude fiscal, señalado por Sainz de Bujanda como el más potente que existe para acabar con esta lacra. Ello tendría como resultado la eliminación de desconfianzas entre el contribuyente y la Administración, con el fortalecimiento del Estado social y democrático de Derecho. Sin embargo, la implantación de esta pretendida educación fiscal es una asignatura pendiente para Espańa, pues aún no se ha conseguido desarrollar adecuadamente. De esta forma, la educación tributaria se convierte en una necesidad imperiosa para eliminar el fraude fiscal, pues facilitaría el cumplimiento voluntario de las obligaciones fiscales y contribuiría al mantenimiento de un sistema tributario justo, como establece la Constitución.

Palabras Clave: fraude fiscal, educación cívico-tributaria, contribuyente, Administración Tributaria, justicia.

\author{
CIVIC TAX EDUCATION: \\ A FORGOTTEN SUBJECT AND NECESSARY TOOL \\ AGAINST TAX FRAUD
}

\section{Abstract}

Civic tax education is a necessary step in the process of addressing and thusly reducing tax fraud. According to Sainz de Bujanda, it is in fact the most powerful instrument to bring an end not only to tax evasion and fraud but also to the mistrust between taxpayers and the Administration. However, in Spain introducing civic tax education has been a forgotten subject. Thereby, civic tax education becomes a fundamental pillar in improving our country and eradicating tax fraud, by gaining the voluntary compliance to tax obligations. This would contribute to maintaining a fair tax system, as established in the Constitution. KeYwORds: tax fraud, civic tax education, taxpayers, Tax Administration, justice. 


\section{INTRODUCCIÓN}

La participación de la ciudadanía en el esfuerzo común de financiar el gasto público ha estado presente en todos los textos del constitucionalismo español. En el artículo 8 de la Constitución de 1812 se establecía que «está obligado todo español sin distinción alguna a contribuir en proporción de sus haberes para los gastos del Estado", de donde arranca la consagración constitucional del deber que incumbe a todos y todas de ser partícipes en el sostenimiento del gasto público, y que encuentra su último hito, por el momento, en el artículo 31.1 de la Constitución de 1978: «todos contribuirán al sostenimiento de los gastos públicos de acuerdo con su capacidad económica mediante un sistema tributario justo inspirado en los principios de igualdad y progresividad que, en ningún caso, tendrá alcance confiscatorio».

Lo que late en esos preceptos constitucionales es el deber de contribuir, el deber que incumbe a la ciudadanía en su conjunto de participar con sus ingresos en la financiación del gasto público, siendo el tributo el instrumento a través del cual se realiza efectivamente tal deber. De la pluralidad de perspectivas desde las que puede ser analizado el deber de contribuir, en el presente trabajo ponemos el foco en su relación con la educación cívico-tributaria, a fin de explicar cómo en un Estado social y democrático de Derecho, prestaciones patrimoniales que son impuestas coactivamente al ciudadano ha de procurarse que sean cumplidas por éste espontáneamente, desde su convicción de que, más allá de cumplir con un deber que le viene impuesto por la Ley, está realizando el principio de solidaridad, que despliega una fuerza motriz a lo largo de nuestra Constitución, como elemento consustancial al ideal de justicia.

$\mathrm{Al}$ abordar la educación cívico-tributaria, una primera reflexión se impone: no se pretende en estas páginas realizar un análisis de cómo y de qué manera el ordenamiento jurídico establece que deban ser cumplidas las obligaciones y los deberes que, a cargo de los ciudadanos, establecen las normas tributarias; nuestra exposición arranca del concepto de educación tributaria tal como lo construyó a partir de 1966 el profesor Sainz de Bujanda, situándolo en el plano de la «personalidad considerada en bloque, y no al comportamiento de los individuos considerados tan solo como sujetos pasivos de obligaciones o deberes nacidos a su cargo por imperativos de ciertos preceptos del ordenamiento positivo»" La educación tributaria, como precisaba el maestro, es parte de la educación, del proceso educativo que, como destacara García Hoz, busca "una modificación del hombre» que signifique «de alguna manera, un mejoramiento, un desenvolvimiento de las posibilida-

* Este trabajo, que obtuvo el Premio de Estudios Jurídicos Don Felipe González Vicén (2019), forma parte del proyecto de $\mathrm{I}+\mathrm{D}+\mathrm{i}$ denominado «Vulnerabilidad, precariedad y brechas sociales. ¿Hacia una redefinición de los derechos fundamentales?» (PID2020-114718RB-I00), financiado por el Ministerio de Ciencia e Innovación del Gobierno de España. Se ha tratado de mantener, en lo posible, el texto original del trabajo premiado.

${ }^{1}$ Sainz de Bujanda, F., Hacienda y Derecho, Volumen 5. ${ }^{\circ}$; Instituto de Estudios Políticos, Madrid, 1967, p. 84. 
des del ser o un acercamiento del hombre a lo que constituye su propia finalidad. La idea de perfección se encuentra, en suma, en la base del proceso educativo ${ }^{2}$. Si la educación cívico-tributaria persigue la transformación de la ciudadanía, la cuestión radica en dilucidar cuándo deba entenderse que el contribuyente está educado tributariamente, lo que nos sitúa en el plano del perfeccionamiento ético-político del ciudadano en el ámbito tributario.

Ese perfeccionamiento no es predicable en términos absolutos, sino que habrá que analizarlo en sede de un ordenamiento jurídico tributario concreto y desde la perspectiva de los valores y principios constitucionales a los que tal ordenamiento se vincula. En otras palabras: la educación cívico-tributaria es, ha de estar, al servicio del Estado social, tal y como lo proclama y estructura nuestra Constitución.

\section{EL ESTADO SOCIAL COMO ESTADO FISCAL}

En lo que se refiere al artículo 1 de la Constitución, conforme al cual «Espańa se constituye en un Estado social y democrático de Derecho, que propugna como valores superiores de su ordenamiento jurídico la libertad, la justicia, la igualdad y el pluralismo político», ha señalado el profesor Rodríguez Bereijo que no contiene una simple calificación retórica de España como tal Estado social y democrático de Derecho, sino que integra un auténtico principio constitucional que vincula a los poderes públicos. Entiende que el Estado social debe tomar la forma de un Estado fiscal, en el sentido de que las potestades tributarias y de gasto público permiten aportar los elementos necesarios para la consecución de un orden social más justo, en tanto que las políticas que integran el Estado social implican un gasto, cuya financiación demanda recursos financieros que la propia Constitución quiere que preferentemente sean aportados por los propios ciudadanos cumpliendo con el deber de contribuir ${ }^{3}$.

Dada la limitación de recursos, la realización del Estado social dependerá de lo financieramente posible, sin que de ello se pueda derivar, como el propio Rodríguez Bereijo destaca, que se pueda limitar un derecho social constitucionalmente reconocido por una alusión abstracta a una situación de crisis económica. La cláusula constitucional de un Estado social y democrático de Derecho es un concepto abierto a múltiples interpretaciones según las diversas opciones políticas, pero no significa que esté vacío de contenido, pues está garantizado por los valores superiores del ordenamiento jurídico, en su sentido material ${ }^{4}$. Buen ejemplo de ello es lo que expresa la exposición de motivos de la Ley territorial 4/2012, de 25 de junio, de

2 García Hoz, V., Principios de pedagogía sistemática, Rialp, Madrid, 1963, p. 17 (cit. por Sainz de Bujanda, F., op. cit., pp. 99).

3 Rodríguez Bereijo, A., La Constitución fiscal de España, Centro de Estudios Políticos y Constitucionales, Madrid, 2015, pp. 46-47.

${ }^{4}$ Rodríguez Bereijo, A., La Constitución..., op. cit., pp. 48-54. 
medidas administrativas y fiscales ${ }^{5}$; cuando explica las razones para aprobar, en un contexto de profunda crisis económica y financiera, una serie de medidas fiscales a aplicar en la Comunidad Autónoma de Canarias:

Somos los ciudadanos los que hemos sido convocados para realizar conjuntamente el esfuerzo solidario para una mayor contribución al sostenimiento de los gastos públicos, garantizando así con nuestros impuestos el mantenimiento de los servicios públicos esenciales. La reducción de las otras fuentes de financiación, especialmente la reducción impuesta en la participación por la Comunidad Autónoma de Canarias en los ingresos del Estado, aboca a adoptar medidas de incremento de la carga fiscal, pues la alternativa a ello sería el desmantelamiento del núcleo esencial del Estado de bienestar.

En relación con la materia tributaria, Rodríguez Bereijo destaca que toda la Hacienda y el proceso de aplicación de los tributos tienen como fundamento el deber general de contribuir de todas las personas al sostenimiento del gasto público, establecido en el artículo 31 de la Constitución. En una valoración conjunta de los preceptos de nuestra Carta Magna, podemos decir que la Hacienda Pública es, además, un instrumento para la redistribución de la renta y la riqueza para conseguir un orden social más justo e igualitario. Por tanto, la función de los tributos pasa, no solo por la financiación de los servicios públicos o la administración, sino que entronca con la redistribución de la riqueza, pudiendo, en cierto modo, entenderse el Derecho Tributario como un conjunto normativo que afecta, preferentemente, a quien tiene mayor capacidad económica; mientras que el Derecho del gasto público pasaría a ser el conjunto normativo relativo, preferentemente, a quienes menor capacidad económica ostentan ${ }^{6}$. En definitiva, a lo que queremos llegar es a lo que finalmente expresa Rodríguez Bereijo después de desarrollar su teoría acerca del Estado fiscal al destacar como función del Derecho Financiero «no tanto (aunque contenga normas de este tipo) prevenir o reprimir comportamientos desviantes o impedir conflictos o facilitar su arreglo una vez surgidos, como la de repartir los recursos disponibles para influir en las condiciones de vida de la sociedad; estimular, incentivar y promocionar los comportamientos de individuos y grupos sociales considerados económica y socialmente ventajosos»?

Esta cita nos invita a reflexionar brevemente sobre la finalidad del Derecho, una cuestión que debería plantearse cualquier persona que sea o aspire a ser jurista. Federico de Castro dejó escrito que las normas jurídicas no eran fines en sí mismos, sino medios para alcanzar otros fines, teniendo en cuenta que el fin último del Derecho es servir al bien común, reflejando el ideal de Justicia y practicando el ideal de

与 BOE núm. 166, de 12 de julio de 2012.

${ }^{6}$ Rodríguez Bereijo, A., La Constitución..., op. cit., pp. 55-58.

7 Rodríguez Bereijo, A., La Constitución..., op. cit., p. 58. La cursiva es nuestra. 
vida contenido en las normas ${ }^{8}$. Por tanto, nos decía Federico de Castro, autor de obligada lectura para entender la Ciencia Jurídica, que el Derecho no solo debía contener una ordenación jurídica general, sino que debía incorporar un deber de conciencia, insistiendo, pues, desde su posición iusnaturalista, en que se debe moralizar el Derecho ${ }^{9}$; una idea que hemos pretendido plasmar en el presente trabajo, cuando insistimos en que el Derecho Tributario debe tener en cuenta la responsabilidad moral o conciencia fiscal del contribuyente. Federico de Castro sintetiza esta crucial idea expresando lo siguiente: «De modo que el Derecho, y consiguientemente la vida social, quede basado no en la pretendida seguridad resultante de unas reglas mecánicas y abstractas, sino en la seguridad que nace de una conducta moral normal, procurada y amparada por el aparato coactivo del Estado ${ }^{10}$. En este mismo sentido, Sainz de Bujanda comenta que

Efectivamente, el ordenamiento jurídico tributario -como cualquier otra parcela del Derecho- no puede limitarse a ser un espejo en el que se refleje, cuidadosamente articulada, la imagen de un grupo social. Existen, por supuesto, unos condicionamientos sociales del mundo jurídico, pero éste se proyecta hacia arriba, apunta hacia unos ideales que inspiran su misión configuradora de la vida social. Sin ese empuje ascensional, el Derecho quedaría aprisionado en el mundo del ser; perdería, en definitiva, su perfil normativo y su fundamentación axiológica. En definitiva, dejaría de ser Derecho ${ }^{11}$.

A la vista de lo expuesto y entrando ya en la materia del presente trabajo, podemos afirmar que una persona está educada tributariamente cuando tenga interiorizado como valor ético que, desde su posición económica y social ventajosa, ha de participar activamente en el reparto de los recursos disponibles; y diríamos más: que rechace cualquier forma de fraude fiscal. El profesor Sainz de Bujanda vinculó su construcción sobre una teoría de la educación tributaria con el fraude, pues en su artículo "Aspectos de la educación tributaria en España»" ${ }^{12}$ dando por hecho que el fraude fiscal alcanzaba por aquel entonces en nuestro país proporciones considerables, se planteaba si la vía educativa podría ser un instrumento eficaz para luchar contra esta lacra, combatiendo la dialéctica que en más de una ocasión parecía existir entre la percepción por los contribuyentes de un «Estado-ladrón» o "Fisco-usurpador", y la que tendría la Administración Tributaria acerca del ciudadano como un «contribuyente-defraudador». Pasan los años y quizás esa dialéctica a la que se refería Sainz de Bujanda siga presente cuando en la conocida como Declaración de Granada, de 18 de mayo de 2018, se denuncia que «parece que el afán recaudatorio se ha convertido en el único objetivo del comportamiento de los órganos tributarios,

8 De Castro y Bravo, F., Compendio de Derecho Civil, Instituto de Estudios Políticos, Madrid, 1966 (obra original publicada en 1949), pp. 16-17.

9 De Castro y Bravo, F., op. cit., p. 17.

10 De Castro y Bravo, F., op. cit., p. 17.

11 Sainz de Bujanda, F., op. cit., p. 245.

12 Sainz de Bujanda, F., op. cit., pp. 149-318. 
con olvido de los derechos y garantías individuales. Lo que debe ser una función pública que tiene como fin hacer efectiva la tributación de todos de acuerdo con la Constitución y las leyes, se lleva a cabo atendiendo de manera preferente a normas reglamentarias e instrucciones internas que, más veces de las deseables, solo están pensadas para allegar más recursos al Erario público, pero no necesariamente para hacerlo de forma más justa $»^{13}$.

Como en la propia Declaración se dice, países como los centroeuropeos tienen «una ciudadanía convencida de que el cumplimiento de las obligaciones tributarias constituye la mejor arma para alcanzar los objetivos sociales y políticos que debe perseguir una sociedad avanzada, además de constituir la mejor defensa frente a políticas populistas ${ }^{14}$; lo que reiteradamente se ha expresado con frase feliz como se es ciudadano porque se es contribuyente y ambas condiciones personales son indisociables. En nuestra opinión, que nuestra ciudadanía no tenga ese convencimiento viene dado, en gran medida, por la perniciosa tendencia de los discursos políticos a huir de los tributos, en tanto que los gobiernos y las oposiciones se marcan como objetivo la reducción o supresión de éstos, convirtiendo en fin lo que no es sino un instrumento: el objetivo no puede ser reducir o aumentar los tributos, pues la decisión previa es qué nivel y calidad de gasto público se pretende, para a continuación decidir cómo se va a financiar y si es posible alcanzar la correspondiente suma de recursos.

Ése es, entendemos, el quid de la educación tributaria: trasladar a la ciudadanía la unidad inescindible del fenómeno financiero, es decir, que se ingresa para gastar; como la realización de políticas públicas comporta necesariamente un gasto, es preciso obtener los recursos dinerarios para cubrirlo; recursos que se obtienen exigiendo de los ciudadanos que cumplan con su deber de contribuir. De este modo, reducir la intensidad de tal deber comporta necesariamente una menor capacidad de financiación y, por tanto, una correlativa reducción de la intensidad y/o calidad del gasto público; la alternativa a ello es que la huida del tributo venga acompañada de una atracción fatal por los ingresos derivados de la emisión de Deuda pública, con las consecuencias que de ello se derivan.

A la dialéctica descrita por Sainz de Bujanda entre el Estado ladrón o Fisco usurpador y el ciudadano defraudador, ha entrado en juego, en mi opinión, un nuevo papel del Estado como denostador de lo tributario.

13 Rodríguez Bereijo, A., Martín Delgado, J.A., Martín Queralt, J., Tejerizo, J.M., Pérez-Royo, F., Cortés, M., et al., «Declaración de Granada», Revista Española de Derecho Financiero (17-34), n. ${ }^{\circ} 179,2018$, pp. 20-21.

14 Rodríguez Bereijo, A., Martín Delgado, J.A., Martín Queralt, J., Tejerizo, J.M., Pérez-Royo, F., Cortés, M., et al., op. cit., p. 19. 


\section{LA DIALÉCTICA ENTRE LA PRESUNCIÓN DEL ESTADO LADRÓN VS. LA DEL CONTRIBUYENTE DEFRAUDADOR}

Recurriendo a los mecanismos de lo que podría denominarse como psicologismo tributario, el profesor Sainz de Bujanda explicó la problemática relativa a la lucha contra el fraude fiscal situando en el centro de su exposición la dialéctica que se suscitaba entre dos presunciones: la del Estado ladrón o Fisco usurpador, por una parte; y la del contribuyente defraudador, por otra.

Lo primero que hemos de precisar es que Sainz de Bujanda no utiliza el término presunción en un sentido técnico jurídico estricto, sino que, con el mismo, se refería a los estados de opinión, basados en más de una ocasión en meros prejuicios, que incidían decisivamente sobre los comportamientos de los contribuyentes y la Administración Tributaria. Con esas expresiones se refería Sainz de Bujanda a lo que en algunos textos legislativos de aquella época -1966- se invocaba como la «idiosincrasia» del pueblo español, y que, para algunos ciudadanos, servía como cobertura moral con la que justificar el incumplimiento de sus obligaciones fiscales, al mismo tiempo que se diseñaba un modelo de sistema tributario y de gestión del mismo adaptado a la desconfianza que los contribuyentes merecían de la Administración. Esa dialéctica a lo único que conducía era a una degradación de la pedagogía tributaria, pues al mantener esos prejuicios una vigencia secular en el seno de la sociedad y no combatirlos adecuadamente, se mantendría el problema del fraude fiscal en el tiempo "si la Administración no se decide a poner en ello un sincero y decidido empeño $»^{15}$.

\subsection{La PRESUnCión del FisCo USURPADOR O DEL ESTADO LADRÓN}

En primer lugar, Sainz de Bujanda aborda el pensamiento que tenía -tieneuna parte de la ciudadanía acerca del Estado, al considerar que la Hacienda no administra lo suficientemente bien el dinero público que recauda de la ciudadanía a través de los tributos, en tanto que destina buena parte de los ingresos tributarios a gastos que merecen la calificación de improductivos, pues no tienen como fin alcanzar el interés general. Incluso, ese grupo de ciudadanos destaca la falta de honestidad por parte del Estado en la gestión de los recursos públicos ${ }^{16}$.

De esta forma, al presumir algunos contribuyentes que el Estado malgasta el dinero público que detrae de sus economías, encuentran una justificación para incumplir sus obligaciones tributarias; justifican, por tanto, el fraude fiscal en su desconfianza en el Estado para gestionar con responsabilidad los recursos de la colectividad. Al fin y a la postre, presumen que la Hacienda Pública usurpa su dinero para utilizarlo, no en beneficio de la colectividad, como debería, sino,

\footnotetext{
15 Sainz de Bujanda, F., op. cit.; p. 197.
}

16 Sainz de Bujanda, F., op. cit., p. 125. 
todo lo contrario, en cuestiones que no reportan en el bien común y, como consecuencia de ello, se consideran legitimados para no cumplir con sus obligaciones para con el Fisco.

Sainz de Bujanda considera que esta presunción de desconfianza de los contribuyentes en el Estado es una constante que no deja de tener manifestaciones a lo largo de nuestra historia, como lo demuestra la actitud que adoptan algunos sectores de la sociedad ante las propuestas en materia tributaria. Así, la ciudadanía rechaza que sus decisiones económicas sean gravadas para obtener recursos públicos, al entender que existe una desigualdad en la distribución de la carga impositiva, que no cumple con la exigencia de progresividad. Por otro lado, también pone su atención en la inadecuada gestión de los ingresos tributarios, por un lado, señalando los excesos en el gasto por parte del Estado para poner en marcha servicios que se estiman como innecesarios o que podrían ser prestados a menores costes o, por otro, denunciando, desde las concretas posiciones ideológicas, que se utilicen esos recursos para apuntalar y reforzar los privilegios de ciertos sectores, que, en la actualidad, cobran especial relevancia cuando se identifican con los de la clase política.

Todo ello manifiesta, según Sainz de Bujanda, unos efectos profundamente nocivos, entre los que sobre todo destaca, no solo el incumplimiento de las obligaciones tributarias por parte de los contribuyentes o, lo que es lo mismo, el fraude fiscal, sino, lo que es más grave, la falta de confianza de éstos en el Estado como ente que tiene como principal objetivo la gestión responsable de los recursos de la colectividad, a través de la actividad financiera, con vistas a satisfacer el interés general. Se rompe así, en cierta medida, el contrato social en virtud del cual los individuos confían en el Estado para satisfacer sus necesidades colectivas sobre las individuales ${ }^{17}$, a través del pago de los tributos, en los términos previstos en la legislación vigente.

Ante la existencia en la sociedad de esos estados de opinión sobre la actuación del Estado en el ámbito de lo financiero, Sainz de Bujanda considera que lo fundamental no es combatir el fraude fiscal a través de medidas represivas, sino que procede analizar los motivos por los que la ciudadanía incide en tales conductas defraudadoras, siendo uno de tales motivos la presunción a la que nos venimos refiriendo de que el Estado no gestiona bien lo público, por lo que es conveniente combatir estas generalizaciones para generar un cambio de actitud en la población y acabar así con el fraude fiscal. Retomaremos este punto en las soluciones propuestas para erradicar el mecanismo de las presunciones.

Al mismo tiempo que Sainz de Bujanda considera que estas generalizaciones de un sector de la población son rotundamente falsas, aconseja al Estado alejarse de ciertas actividades que alimentan este supuesto prejuicio tan dańino para el Estado de Derecho. Dicho de otro modo, expresa literalmente que «el método educativo por excelencia es la probidad en el manejo del producto fiscal $»^{18}$, lo que

17 Bravo Cucci, J., Derecho Tributario. Reflexiones; Jurista editores, Perú, 2018, p. 28.

18 Sainz de Bujanda, F., op. cit., p. 126. 
coloquialmente se conoce como predicar con el ejemplo, y se refiere concretamente a evitar actividades para favorecer económicamente a determinados grupos o entidades, en lugar de a la colectividad.

\subsection{LA PRESUNCIÓN DEL CONTRIBUYENTE DEFRAUDADOR}

Hemos hablado de una dialéctica, por lo que el mecanismo de las presunciones en el ámbito tributario no se agota con la que acabamos de señalar, sino que a ella se suma la presunción inversa, en virtud de la cual la Administración entiende que el contribuyente es, por norma, un defraudador, es decir, que no cumple con sus obligaciones tributarias. Es lo que algunos autores han venido denominando el principio de la incredulidad sistemática respecto de la veracidad de lo que declaran los contribuyentes y que se utiliza por la Administración como un elemento esencial en el que fundamentar sus medidas represivas para luchar contra el fraude fiscal ${ }^{19}$.

Al presumir la Administración que los ciudadanos defraudan, ineludiblemente, una cierta cantidad de dinero que, por ley, debiera ingresarse en cumplimiento de sus obligaciones tributarias, en el proceso de elaboración de las normas reguladoras de los tributos se aprueban normativas cuyo fundamento está en compensar ese nivel de fraude que se presume, mediante reglas ciertamente injustas, pues no encuentran su fundamento en la realización efectiva de los principios constitucionales tributarios, sino en lograr un nivel de recaudación dado, amortizando, vía normativa, el efecto del fraude. En este sentido, podemos señalar como ejemplos la decisión de elevar las bases imponibles y/o los tipos de gravamen, con el fin de obtener la recaudación esperada en caso de no existir ese supuesto nivel de fraude.

Si nos preguntamos por la intensidad en que cada una de las presunciones que entran en dialéctica despliega sus efectos, Sainz de Bujanda se inclina por dar mayor peso a la del ciudadano defraudador, hasta el punto de que la misma ha quedado recogida expresamente en textos positivos en más de una ocasión. Cabe señalar al respecto la Ley de 26 de diciembre de 1957, por la que se formalizó una de las grandes reformas de nuestro sistema tributario ${ }^{20}$, en la que, al asumir el legislador la presunción del contribuyente defraudador, se instauró, como fórmula de lucha contra el fraude, el régimen de convenios y evaluaciones globales sobre cuotas y bases, mediante cálculos que, en determinados casos, se llevarían a cabo a través de decisiones tomadas por un Jurado tributario, al margen de la propia estructura del tributo, sin que apenas quedase posibilidad para probar lo contario por parte del contribuyente, pues tales Jurados tomaban sus decisiones en conciencia, cuestión que poco los apartaba de los Tribunales de honor.

19 Sainz de Bujanda, F., op. cit., p. 129.

${ }^{20}$ Ley de 26 de diciembre de 1957, por la que se aprueban los Presupuestos Generales del Estado para el bienio 1958-1959, y reformas tributarias (BOE núm. 323, de 27 de diciembre de 1957). 
Pues bien, esta presunción, al igual que la del Estado ladrón o Fisco usurpador, ocasiona efectos profundamente nocivos para la educación tributaria y el valor de solidaridad que debe fundamentarla; a mayor abundamiento, incorporar a nuestra legislación la presunción del ciudadano defraudador como eje matriz de la misma lleva, paradójicamente, al efecto contrario al pretendido, pues el ciudadano, a la vista de decisiones normativas que alteran el adecuado juego de los principios tributarios, se siente legitimado para incorporar por su parte la distorsión en la declaración de sus datos fiscales. Dicho de otro modo: si los contribuyentes, incluso los cumplidores, toman conciencia de que la Administración, para obtener una determinada recaudación, presupone un nivel de fraude en sus declaraciones, aquéllos reducirán la cuantía de las mismas, por lo que se incurrirá en lo que precisamente se pretendía evitar: la mentira fiscal, el fraude fiscal. La vacuna acaba convirtiéndose en el veneno que corroe a nuestro sistema tributario. Se trata, por tanto, de un ciclo sin fin de recíprocas desconfianzas, que, en lugar de frenar, dan aliento a las conductas defraudadoras, provocadas por la falta de educación cívico-tributaria.

\subsection{VISIÓN GLOBAL SINTETIZADORA DE LAS PRESUNCIONES}

Antes de abordar las soluciones planteadas para resolver el problema expuesto, parece adecuado que tengamos una visión global que sintetice el mecanismo de las presunciones sobre los comportamientos y actitudes de contribuyentes y Administración, respectivamente. Sainz de Bujanda resume a la perfección lo que he tratado de explicar con estas certeras palabras:

El contribuyente, de una parte, oculta la riqueza imponible, porque presume que el Fisco no reparte equitativamente la carga fiscal o no emplea con justicia las sumas que obtiene, y, de otra parte, la Hacienda concede escaso valor -tanto en el terreno normativo, como en la aplicación práctica- a las declaraciones y a los datos que el contribuyente le procura, porque presume que éste defrauda. En la medida en que ambas presunciones se dilatan y vigorizan, decrece la educación tributaria, hasta casi desaparecer cuando aquéllas se generalizan, esto es, cuando los supuestos en los que no operan son tan escasos que su intervención puede reputarse nula o insignificante a la hora de caracterizar un sistema tributario o unos hábitos fiscales ${ }^{21}$.

En la línea marcada por Sainz de Bujanda, podemos comprobar a partir del esquema de la página siguiente (ilustración 1), de elaboración propia, cómo funciona la dialéctica de las presunciones que ya explicó a mediados del siglo pasado el hacedor de la teoría a partir de la cual hoy realizamos la presente investigación:

${ }^{21}$ Sainz de Bujanda, F., op. cit., p. 196. La cursiva es nuestra. 


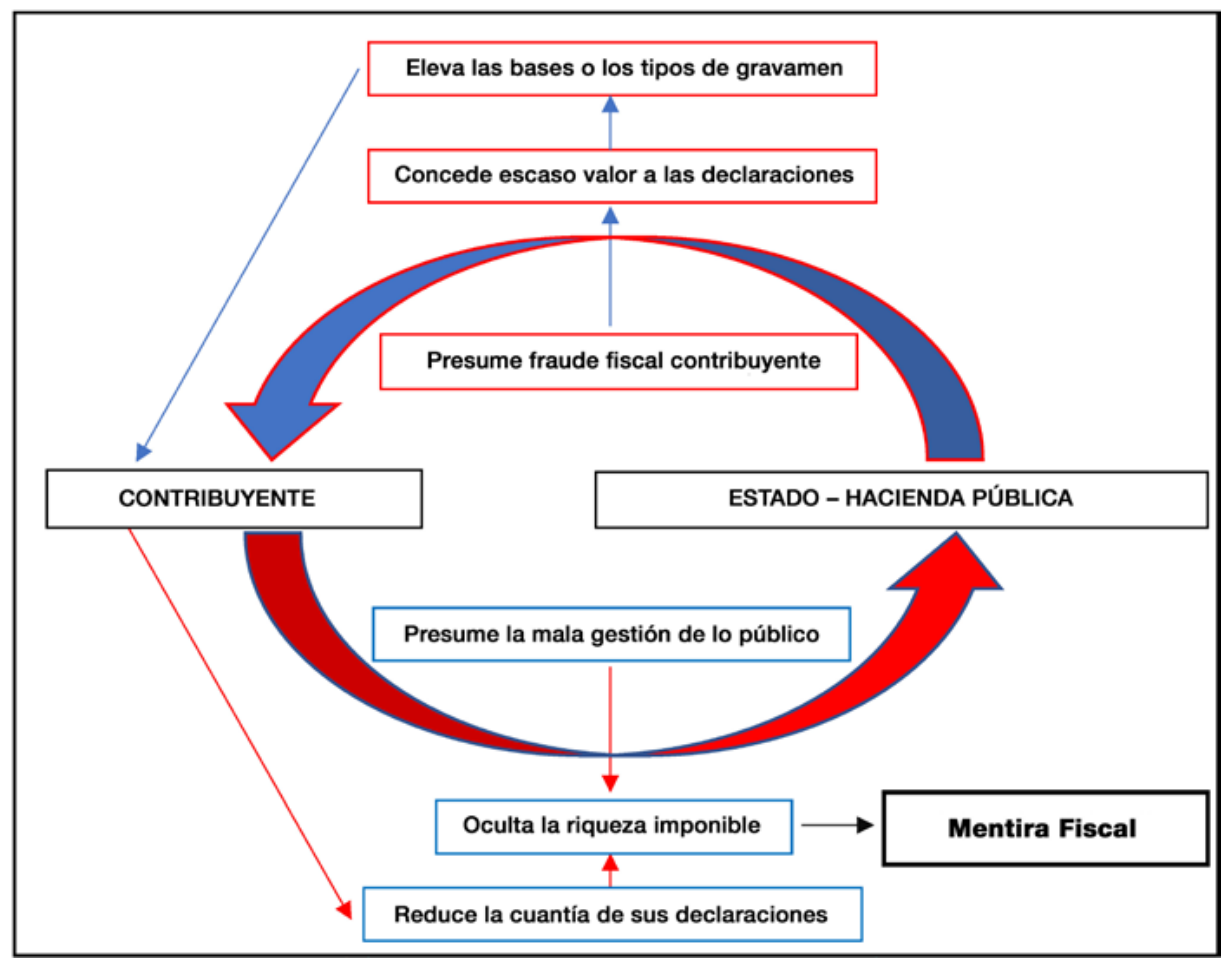

Ilustración 1. Esquema del mecanismo de las presunciones de Sainz de Bujanda. Fuente: elaboración propia.

\subsection{REMEDIOS PROPUESTOS PARA RESOLVER ESTE PROBLEMA DESDE LA EDUCACIÓN} TRIBUTARIA Y SUS PREVISIBLES RESULTADOS

Tras estudiar detalladamente los efectos de las presunciones del Estado ladrón o Fisco usurpador y del ciudadano defraudador en lo que respecta a la aplicación del sistema tributario y, por extensión, en la elaboración de la normativa tributaria, Sainz de Bujanda pasó a centrar su atención en la exposición de algunas medidas que pudieran ser utilizadas para erradicar tales presunciones y los nocivos efectos que las mismas generaban. En todos estos posibles remedios encontramos una línea de pensamiento que los cohesionan, ya que todos ellos quedan al servicio de profundizar en la educación tributaria, por lo que el profesor pone sobre la mesa los resultados que pueden derivarse de la introducción de una educación tributaria de signo social en España.

En primer lugar, para acabar con la presunción del Estado ladrón o del Fisco usurpador, Sainz de Bujanda propone trabajar en dos vías diferentes: el fortalecimiento de la justicia distributiva en la imposición y el refuerzo de la institución 
presupuestaria. Parece lógico que, si la ciudadanía desconfía de la Administración porque entiende que hay un reparto injusto y desigual de la carga impositiva, la tarea del legislativo ha de centrar sus esfuerzos en mejorar la justicia en la imposición.

En este sentido, la ciudadanía ha asumido que, por lo general, contribuye en demasía a las arcas públicas a través de sus ingresos tributarios, pues, en tanto que desconoce la comparación entre su contribución y la del resto de ciudadanos, presume lo que escuchamos de forma cotidiana con expresiones como la de «los ricos no pagan». Lejos de entrar a valorar si esta opinión generalizada es o no correcta, lo cual debería ser objeto de un análisis exhaustivo más propio de la Ciencia de la Hacienda Pública, lo cierto es que más allá de los slogans resulta imprescindible la realización de estudios por parte de la Universidad o del Instituto de Estudios Fiscales, en los que se acredite de forma fehaciente la contribución de la ciudadanía por tramos de renta, integrando la carga tributaria total -impuestos directos e indirectos-; y centrándose en los contribuyentes personas físicas, sin mezclar a éstos con la contribución de las sociedades -que es una contribución medial, pues, en definitiva, la renta es en última instancia del socio y no de la sociedad-. Así, resultaría más provechoso en cuanto a la educación tributaria de los contribuyentes que, en lugar de colocar en el centro del debate público las decisiones políticas sobre la dicotomía de subir o bajar los impuestos, se explicase de forma clara y concisa a la ciudadanía, por ejemplo, el concepto y funcionamiento de los impuestos sobre el consumo, y de la operativa del sistema de retenciones a cuenta y su efecto «a devolver» en la correspondiente autoliquidación del Impuesto sobre la Renta de las Personas Físicas.

En concreto, Sainz de Bujanda se detiene en los mecanismos que nos permitirían reforzar la visión de la ciudadanía en el Presupuesto como institución, remedio en el que nos centraremos especialmente por su importancia capital para la disciplina jurídica sobre la que versa este trabajo. Según el profesor, para acabar con la presunción del Estado ladrón o Fisco usurpador, debe reforzarse la institución presupuestaria, a través de la transparencia y la publicidad, mediante la información, de forma clara y sencilla a la ciudadanía, de los ingresos obtenidos y los gastos efectuados, así como la afectación de los ingresos a destinos que vengan previamente determinados de forma específica en el Presupuesto, sobre todo si estos ingresos tributarios se producen como consecuencia de la prestación de servicios públicos ${ }^{22}$.

Como sabemos, el Presupuesto ${ }^{23}$ es, antes que nada, una norma jurídica, por cuanto podemos definirlo, según Rodríguez Bereijo, como «el acto legislativo mediante el cual se autoriza el montante máximo de los gastos que el Gobierno puede realizar durante un período de tiempo determinado en las atenciones que detalladamente se especifican y se prevén los ingresos necesarios para cubrirlos» ${ }^{24}$. De esta forma, Rodríguez Bereijo expresaba que el Presupuesto del Estado abarca el ciclo

22 Sainz de Bujanda, F., op. cit., pp. 217-223.

23 Escribimos Presupuesto así, con mayúsculas, siguiendo a los autores que citamos en estas líneas, por estarnos refiriendo al Presupuesto del Estado como institución jurídica.

${ }^{24}$ Rodríguez Bereijo, A., El Presupuesto del Estado, Tecnos, Madrid, 1970, p. 19. La cursiva es nuestra. 
financiero completo, desde la detracción de riqueza de las economías privadas para convertirla en ingresos públicos, con el fin de cubrir los gastos propios de las necesidades colectivas, hasta la transformación de dichos ingresos en servicios públicos ${ }^{25}$; una idea que pone el foco en la unión inexorable existente entre el ingreso y el gasto.

Sin embargo, también debemos decir que el Presupuesto, además de una norma jurídica, es un documento informativo, en tanto que en el mismo se refleja el programa de actuación que el legislativo marca al ejecutivo para un ejercicio determinado, de suerte que el contribuyente ha de ser capaz de derivar del mismo las acciones que el ejecutivo ha de realizar; y es, en este sentido, a lo que se refiere Sainz de Bujanda cuando destaca que debemos profundizar en la publicidad del Presupuesto para que la ciudadanía tenga suficiente información acerca del destino de los gastos públicos, en aras de la eliminación de la presunción del Estado ladrón o Fisco usurpador. Rodríguez Bereijo entiende también que una estructura presupuestaria debe responder, entre otras, a la exigencia de ofrecer el cuadro más exacto posible de los ingresos y gastos públicos a realizar durante el ejercicio presupuestario, con un grado suficiente de especificación, con el fin de que los contribuyentes conozcan la distribución de los impuestos que inciden sobre sus economías ${ }^{26}$; ingresos públicos que deben servir para la satisfacción de necesidades públicas a través del gasto.

Por otro lado, Sainz de Bujanda aclaraba a este respecto que «es ineludible no confundir la propaganda con la información $\aleph^{27}$, teniendo en cuenta que la primera no ayuda en nada a la ingente tarea que tenemos por delante para erradicar la dialéctica de las presunciones, mediante la educación cívico-tributaria. Es a lo que también se refiere Ferreiro cuando critica el recurso frecuente en el ámbito fiscal a "normas propaganda», es decir, normas vacías de un contenido jurídico que no incorporan innovaciones en el ordenamiento que las haga realmente necesarias, sino que pretenden fundamentalmente "la propaganda política de la acción del Gobierno", lo cual complica la sencillez del sistema tributario, teniendo en cuenta que éstas no añaden nada al contenido de la ley, sino, más bien al contrario, la complican y la convierten en ininteligible para la ciudadanía ${ }^{28}$. Un ejemplo de ello, en el ámbito que nos ocupa en estas líneas, es una campaña impulsada en 2019 por la Consejería de Economía y Hacienda del Gobierno de Canarias, titulada literalmente «Bajamos los impuestos", que tenía como objetivo difundir información sobre las ventajas fiscales para los contribuyentes introducidas en los Presupuestos Generales de la Comunidad Autónoma ${ }^{29}$. No entraremos a valorar los objetivos de las medidas fiscales que

25 Rodríguez Bereijo, A., El Presupuesto..., op. cit. p. 15.

${ }^{26}$ Rodríguez Bereijo, A., El Presupuesto..., op. cit., pp. 23-38.

27 Sainz de Bujanda, F., op. cit., p. 133.

${ }^{28}$ Ferreiro Lapatza, J.J., Ensayos sobre metodología y técnica juridica en el Derecho Financiero y Tributario, Marcial Pons, Madrid, 1998, pp. 36-37.

${ }_{29}$ Toda la información sobre la campaña acerca de la rebaja fiscal está disponible en https:// bit.ly/2oQgTzV. 
pretende difundir esta campaña ${ }^{30}$, los cuales, según la misma, pasan por la recuperación económica de las familias y la redistribución de la riqueza, a través de una serie de exenciones en el Impuesto General Indirecto Canario (IGIC) y de deducciones en la cuota íntegra del Impuesto sobre la Renta de las Personas Físicas (IRPF); pero resulta cuando menos llamativo que todo cuanto pretende transmitir el Gobierno a la ciudadanía con respecto a los presupuestos (con la importancia que trae consigo, como ya hemos destacado, esta institución) es que se van a bajar los impuestos, con un lema que parece más propio de una publicidad bancaria que de un ejecutivo autonómico ("con las nuevas ventajas fiscales, tú sales ganando»), en lugar de informar con claridad a los ciudadanos a través del Presupuesto acerca de los servicios y bienes públicos que se van a suministrar, esto es, de las políticas que ha de ejecutar el Gobierno por mandato del Parlamento expresado en la Ley de Presupuestos, es decir, en qué se van a emplear los recursos públicos obtenidos a través de los tributos pagados por los contribuyentes; un método educativo que, como ya comentamos, es una de las recomendaciones que propone Sainz de Bujanda como remedio a los problemas a los que nos hemos referido, para potenciar la conciencia tributaria.

Esta actitud de los partidos políticos -y, creemos que podemos afirmar, sin excepción alguna- hacia lo tributario, proponiendo respecto de los mismos reducciones sucesivas, y presentando ante los ciudadanos como un éxito cualquier rebaja fiscal, es el peor servicio que pueda prestarse a los objetivos de una pedagogía tributaria, pues sucesivas medidas legislativas únicamente orientadas a satisfacer las exigencias del marketing, tomadas en más de una ocasión a demanda de grupos de presión, desdibujan lo que es la lógica interna que debe presidir un conjunto de tributos merecedor de la calificación de sistema tributario. En la situación que describimos lo que encontramos es lo que la ciencia política explica como la sustitución del político de oferta-aquél que es capaz de diseñar una propuesta de configuración de la sociedad-por el político de demanda-que, carente de proyecto, se limita a recibir lo que la sociedad quiere y responderle dándole satisfacción-; cuando desaparecen

${ }^{30}$ Aunque sí que debemos alertar sobre los peligrosos efectos que tendría para nuestros servicios públicos la decisión de proceder a una bajada de impuestos, lo cual finalmente no beneficiaría a la población. No debemos olvidar que la Consejería de Hacienda realiza una labor instrumental en la estructura orgánica del Gobierno de Canarias, pues su objetivo no es otro que el de recaudar los recursos suficientes para financiar los servicios públicos, que serán ejecutados por el resto de consejerías del ejecutivo autonómico (en una actividad finalista). En este sentido, el Gobierno, para optar por bajar los impuestos, debe informar a la ciudadanía sobre dos cuestiones previas: o bien ha logrado que los servicios públicos se presten a un menor coste, necesitando menos recursos para la prestación de los mismos; o bien va a reducir la cobertura y calidad de los servicios públicos, al dotarlos de una menor financiación, ante la falta de recaudación que supone dejar de percibir ingresos tributarios a causa de la bajada de los impuestos (también podría informar, en su caso, de que ha obtenido ingresos por otras vías distintas de la preferente para la financiación de los gastos públicos). Resulta como mínimo cuestionable que, con la situación en la que se encuentra actualmente nuestra Comunidad Autónoma con respecto a los servicios públicos (listas de espera en la sanidad, recortes en educación y dependencia...), sea conveniente la bajada de los impuestos, pero resulta aún más preocupante que el Gobierno no haya explicado los motivos (más allá de los meramente propagandísticos), en la línea de los comentados, que le llevan a tomar esta decisión. 
las propuestas de configuración de la sociedad, lo que desaparecen son los ideales éticos y de justicia. Una vez más, Sainz de Bujanda supo describir la situación en la que hoy nos encontramos:

Sólo en la medida en que esos ideales éticos y de justicia estén presentes en la tarea legislativa, actuará ésta como instrumento de educación tributaria, y esa misión habrá de cumplirla aún a costa de inevitables choques y enfrentamientos con aquellos sectores sociales que más llamados estén al sacrificio, para que el mejoramiento de la vida colectiva llegue a producirse. A la inversa, en la medida en que la legislación renuncie a ejercer su función configuradora del contorno social, y busque tan sólo en éste la línea de menor resistencia, su papel será negativo en el proceso de la educación tributaria. Dado que entonces la propia normativa vendrá a consolidar toda clase de egoísmos y de corruptelas ${ }^{31}$.

Es por esto por lo que a la dialéctica que planteaba el profesor entre el Estado ladrón y el contribuyente defraudador, entendemos que en los momentos actuales hay que sumar la realidad de un Estado denostador de lo tributario, que no implícitamente, sino de manera expresa y clara, ha adoptado una posición beligerante contra lo tributario. Con tal posición, los poderes públicos -y los partidos políticos, ya estén en la oposición o en responsabilidades de Gobierno- lo que han hecho es sembrar la simiente que ha ido germinando en una actitud cada vez más reacia por la ciudadanía hacia los tributos.

A los remedios planteados por Sainz de Bujanda para acabar con la presunción Estado ladrón, entiendo que cabría sumar, con respecto al presupuesto, específicamente en el ámbito municipal, dada su complejidad en niveles territoriales superiores, el impulso de medidas como la participación ciudadana en la toma de decisiones sobre el destino de los gastos públicos con iniciativas, por ejemplo, como la de los presupuestos participativos, que no solo fomentarían la publicidad, sino también la corresponsabilidad de la ciudadanía, en la gestión de los recursos públicos ${ }^{32}$. En el sentido expuesto, el artículo 17 de la Ley 7/2015, de 1 de abril, de los municipios de Canarias ${ }^{33}$, plantea como uno de los medios para el ejercicio de la participación ciudadana en los Ayuntamientos de Canarias los presupuestos participativos (Art. 17.1, letra L, de la Ley), para que, a través de las Juntas de Distrito, Consejos de barrio o sector, Consejos de participación ciudadana o asociaciones vecinales, la ciudadanía pueda «formular programas de necesidades vecinales valorados económicamente que, una vez aceptados por el órgano correspondiente de los citados, serán elevados al Área de Gobierno competente en materia de hacienda para su consideración y, en su caso, integración en el presupuesto general de la corporación».

31 Sainz de Bujanda, F., op. cit., pp. 245-246.

32 Calvo Vérgez, J., La experiencia de los presupuestos participativos en los entes locales; Colección Fiscalidad Dykinson, Madrid, 2011, pp. 81-83.

${ }^{33}$ BOC núm. 70, de 14 de abril de 2015; BOE núm. 101, de 28 de abril de 2015. 
Por otro lado, la extirpación definitiva de la presunción, en este caso, del contribuyente defraudador, imprescindible para implementar y mejorar la educación tributaria, debería pasar, según Sainz de Bujanda, por el reconocimiento de la personalidad moral del contribuyente ${ }^{34}$. Ello exige que el Estado cambie su actitud de desconfianza hacia el ciudadano y, en lugar de mostrar una incredulidad sistemática respecto de lo declarado por los contribuyentes, opte por una «sistemática certidumbre de la veracidad" acerca de sus declaraciones. Es decir, pasar de la presunción contribuyente defraudador a la presunción contribuyente fiel cumplidor de la ley tributaria. Y, a pesar de que considera que esta presunción está mucho más cercana a la realidad que la primera, entiende que debemos poner el foco de forma ineludible en la educación tributaria (y no únicamente en los mecanismos sancionadores) para combatir el fraude fiscal ${ }^{35}$; una cuestión a la que nos referiremos posteriormente al abordar el recurso cada vez más frecuente de la Administración Tributaria a la hora de facilitar el cumplimiento voluntario de los contribuyentes de sus obligaciones tributarias.

Por último, después de plantear éste y otros problemas que perjudican a nuestro sistema tributario (como los peligros del psicologismo fiscal o la escasa política de información tributaria), cuya solución pasa ineludiblemente por el fomento de la educación tributaria, Sainz de Bujanda recoge los principales resultados que, a su juicio, traería consigo para el conjunto de la sociedad el logro de un mejor nivel educativo de los contribuyentes, los cuales esbozaré brevemente a continuación:

a) Justicia y racionalidad del sistema tributario. Un contribuyente tributariamente educado cumpliría con sus obligaciones tributarias, siempre que sean planteadas como idóneas para los fines de justicia y eficacia propios de los tributos. Para lograr la racionalidad del sistema tributario hay que poner el énfasis en los principios de solidaridad y de responsabilidad moral.

b) Simplificación de la Administración financiera. La racionalidad del sistema favorecerá la simplificación de la Administración que lo aplica, que centrará su atención en el perfeccionamiento de las figuras tributarias y no en la persecución del contribuyente, cuya oposición al Fisco se reducirá.

c) Reducción de la conflictividad tributaria. El fin de las desconfianzas entre contribuyentes y Administración Tributaria disminuirá los conflictos jurídicos, logrando que los procesos tributarios tengan un alcance estrictamente interpretativo ${ }^{36}$.

${ }^{34}$ Nos genera ciertas dudas la referencia que hace Sainz de Bujanda a la personalidad moral del contribuyente, pues consideramos que, en realidad, se refiere, como ya lo hace en otras ocasiones, a su responsabilidad moral, haciendo alusión a una consideración de la ética de los contribuyentes como uno de los presupuestos de la educación tributaria. No obstante, hemos preferido mantener lo expresado literalmente por el autor, con los matices que hacemos constar en esta nota.

35 Sainz de Bujanda, F., op. cit., pp. 223-228.

36 Sainz de Bujanda, F., op. cit., pp. 137-141. 
No cabe dar por concluida esta primera parte del análisis de la construcción del profesor Sainz de Bujanda sobre la educación tributaria sin exponer lo que él considera que supone ser un contribuyente educado. Esa cualidad del contribuyente no solo tiene que ver con el cumplimiento de las obligaciones tributarias, sino también con la resistencia u oposición a las actitudes injustas por parte de la Administración Tributaria; añadiríamos por nuestra parte que esa doble perspectiva de la cualidad de educado es la que se corresponde con un contribuyente que, antes que tal, es ciudadano:

El contribuyente, en suma, sólo estará bien educado si, además de cumplir las obligaciones y deberes que el ordenamiento le impone, está dispuesto a velar para que los órganos administrativos actúen con arreglo a Derecho, atajando, con los pertinentes remedios jurídicos, cualquier aplicación arbitraria del tributo. En términos pedagógicos, diríamos, pues, que el contribuyente no está sólo facultado, sino obligado, a exigir que la Administración se comporte con corrección jurídica. El incumplimiento de esta obligación es tan grave-tal vez más grave-que el fraude del tributo ${ }^{37}$.

Se trata, por tanto, como bien expresa el profesor, de una cuestión bidireccional: el Estado debe poner en marcha los mecanismos educativos para que las personas puedan ser contribuyentes tributariamente educados, pero el resultado de esta estrategia no solo debe generar el respetuoso cumplimiento de las obligaciones fiscales por parte del pueblo, sino también la enérgica oposición de éste a cualquier posible vulneración por parte de la Administración de los principios que construyen lo que nuestra Carta Magna denomina sistema tributario justo.

Esta premisa entronca directamente con la concepción dogmática del tributo en relación con la categoría jurídica de la obligación que tan acertadamente introdujo en nuestro país Sainz de Bujanda. El tributo no es, como defendía Otto Mayer en el siglo XIX, una simple relación de poder, en la que el individuo está vinculado al Estado por una situación jurídica de sujeción general, en virtud de la cual quedaba sujeto a obedecer y cumplir las pretensiones de la Administración financiera, por una cuestión de supremacía. Cuando decimos que el contribuyente no solo tiene la posibilidad de cumplir sus obligaciones, sino la obligación de resistir ante las injusticias, estamos diciendo, como bien nos explica Nawiasky ${ }^{38}$, que el contribuyente (acreedor tributario) está en un plano de igualdad con la Administración (deudor tributario), pues ambos quedan sujetos de igual manera en cuanto a sus derechos y obligaciones al Derecho, sus posiciones jurídicas derivan de las normas del ordenamiento jurídico; de tal forma que es falso que el Estado esté en una posición superior al deudor, pues debe ajustarse a la estricta aplicación de las normas jurídicas que, como ya hemos dicho, vinculan igualmente al ciudadano y a la Administración.

37 Sainz de Bujanda, F., op. cit., p. 155. La cursiva es nuestra.

${ }^{38}$ Nawiasky, H., Cuestiones Fundamentales de Derecho Tributario (Juan Ramallo, trad.), Instituto de Estudios Fiscales, Madrid, 1982 (obra original publicada en 1926), pp. 52-54. 
Al fin y al cabo, volviendo a lo que exponía Sainz de Bujanda, la educación no significa únicamente enseñar a obedecer, sino a tener pensamiento crítico, a reflexionar y a dudar. Significa enseñar a cumplir, sí, pero también a resistir con todos los medios admitidos en Derecho ante las injusticias. Dicho de otro modo, en palabras de Sainz de Bujanda: «Despertar y avivar la conciencia, en vez de adormecerla, es el gran método educativo ${ }^{39}$.

\section{LA VIGENCIA DE LOS PLANTEAMIENTOS DE SAINZ DE BUJANDA}

Cuando tantas veces se califica a propuestas o iniciativas como «modernas», y tal es el caso de las campañas dirigidas a la educación cívico-tributaria, es necesario destacar, como se hace en la Declaración de Granada, el esfuerzo intelectual que a lo largo de los años 50 y 60 del siglo pasado hicieron juristas de la talla del profesor Sainz de Bujanda para elaborar un arsenal de conceptos que trascienden al momento histórico-político en el que se elaboraron, pues lo fueron sobre los sólidos cimientos de lo que es la dogmática jurídica y el conocimiento pleno e integral del Derecho. La construcción de Sainz de Bujanda sobre la educación cívico-tributaria -y esta afirmación es válida con carácter general para el conjunto de su obra- mantiene actualmente plena vigencia, porque se construyó sobre la decidida apuesta por el imperio de la Ley, poniendo el eje estructurante de su pensamiento en una constante preocupación por el anhelo de la justicia y por los principios propios de un Estado de Derecho. Sainz de Bujanda no se contentaba con realizar un mero análisis del Derecho positivo del momento, sino que construyó las bases del Derecho Financiero, como veremos después, sobre los cimientos de un Estado de Derecho, pensando en los países europeos del entorno, ante las carencias evidentes que tenía España en esa época ${ }^{40}$. Es ésta una cuestión que felizmente se ha destacado en la Declaración de Granada:

Los autores de los años 50 y 60 crearon un Derecho financiero constitucional, propio de un Estado de Derecho, esto es, desarrollaron su actividad «como si» (y es necesario resaltar las comillas) en España existiera entonces un régimen democrático [...]. Por ello, la incorporación de los principios y reglas esenciales del ordenamiento financiero a la Constitución de 1978 se realizó sin apenas discusión parlamenta-

39 Sainz de Bujanda, F., op. cit., p. 120.

${ }^{40}$ No debemos olvidar que Helsen también escribió su gran obra durante los tiempos oscuros de la Alemania nazi, dando cumplida respuesta al estructurar su explicación del tributo sobre las bases del Estado de Derecho. Ello nos demuestra que hay intelectuales que son capaces de elevarse a su tiempo, construyendo teorías que van más allá de lo establecido en un determinado periodo y que, por este motivo, tienen la capacidad de que se mantengan sus construcciones teóricas a lo largo de la historia, como demostramos en este trabajo con las enseñanzas de Sainz de Bujanda. 
ria, ya que el andamiaje conceptual sobre la que se asienta estaba construido, y no fue necesaria otra tarea que trasladarlo materialmente al texto constitucional ${ }^{41}$.

En suma, en el presente apartado nos planteamos si realmente el mecanismo de las presunciones Estado ladrón y contribuyente defraudador sigue estando de actualidad en España, demostrando su vigencia secular. Pues bien, parece claro que, si finalmente concluimos que la dialéctica de las presunciones sigue vigente en la sociedad española del siglo xxI, será un signo evidente que apunte a la urgente necesidad de incorporar ineludiblemente la educación cívico-tributaria en España, por las nocivas consecuencias que está inoculando en la concepción misma de nuestro sistema tributario.

\subsection{El Legado de Sainz de Bujanda}

Los estudios de Sainz de Bujanda sobre la educación tributaria incorporados a su obra Hacienda y Derecho quizás no hayan recibido la misma atención que la doctrina ha dedicado a otras partes de su obra, lo que no quita valor a la brillantez de su análisis sobre esta cuestión. En mi opinión, tales estudios son un hito más, y no de menor entidad, de lo que por muchos es hoy considerado el legado de Sainz de Bujanda, como ha acuñado el profesor Clavijo, en un artículo cuyo título he tomado para rotular el presente apartado, en el que afirmaba con rotundidad su opinión sobre la obra del maestro: «Si cuando él vivía sus tesis eran un punto de referencia obligado para cualquier tributarista, hoy me parece que lo son más ${ }^{42}$. Destaca el profesor Clavijo lo que considera como las cuatro tesis fundamentales que constituyen el legado de Sainz de Bujanda en Derecho Tributario y que debemos continuar difundiendo; a saber: la obligación tributaria como eje dogmático de esta disciplina, el concepto instrumental del procedimiento tributario, la distinción entre Derecho Tributario material y formal y, por último, la existencia de un conglomerado de potestades en el Derecho Tributario.

Considero que el legado de Sainz de Bujanda es tan abundante y valioso que es tarea ardua acotarlo definitivamente, pues, de entre sus ideas, algunas tienen, sin duda, una vigencia indefinida en el tiempo; otras, incluso, cobran especial sentido precisamente por el paso del tiempo. Una de ellas, sin duda, es la que introdujo en los dos capítulos que vehiculan y han inspirado el presente trabajo, sobre la educación tributaria en España.

Sainz de Bujanda, alejándose del momento político que le tocó vivir, tuvo, como otros tantos, la grandeza intelectual de apartarse de lo que, con terminología

${ }^{41}$ Rodríguez Bereijo, A., Martín Delgado, J.A., Martín Queralt, J., Tejerizo, J.M., Pérez-Royo, F., Cortés, M., et al., op. cit., p. 18.

${ }^{42}$ Clavijo, F., «El legado de Sainz de Bujanda en Derecho Tributario», en Fernando Sainz de Bujanda Fundador de los estudios de Derecho Financiero y Tributario (147-156). Servicio de publicaciones. Facultad de Derecho Universidad Complutense de Madrid, Madrid, 2003, p. 147. 
actual, podríamos llamar politicamente correcto para sustentar su construcción teórica sobre los principios democráticos del Estado de Derecho recogidos en las Constituciones de los países de nuestro entorno ${ }^{43}$. Esto queda claro en la severa crítica que dispensa a la Ley de 26 de diciembre de 1957, en la que identificaba el máximo exponente de la presunción del contribuyente defraudador en nuestros textos positivos. No en vano, como recordaba el profesor García Añoveros, don Fernando Sainz de Bujanda fue parte del bando republicano tras el golpe de Estado y la Guerra Civil, para posteriormente adquirir la condición de Letrado de las Cortes ya en la dictadura franquista ${ }^{44}$; pero, tras una lectura detenida de su obra, es más que evidente que su pensamiento y valores no concordaban con el momento político en el que la construyó, teniendo, como hemos comentado, la capacidad de elevarse para construir una dogmática del Derecho Financiero, sobre los cimientos del Estado de Derecho.

La vigencia de los planteamientos del maestro es innegable. Específicamente centrados en su demanda para la incorporación de forma decidida de la educación tributaria en nuestro país, a la vista de los numerosos problemas que aquejaban -aquejan- a nuestro sistema, pretendemos señalar en el apartado siguiente algunos indicios que demuestran que las presunciones Estado ladrón y contribuyente defraudador se han perpetuado en el tiempo, lo cual nos hace llegar a la conclusión de que el mecanismo de las presunciones, al que hemos venido refiriéndonos en apartados precedentes, está más vigente que nunca en la España del siglo XXI, precisamente por la ausencia de una apuesta convencida por parte del Estado para erradicarla. Y, como hemos apuntado, en la actualidad a esa dialéctica se ha sumado en nuestra opinión el nuevo rol del Estado -y de buena parte de la clase política-como agente denostador de lo tributario.

\subsection{LA PELIGROSA DiALÉCTICA DE LAS PRESUNCIONES EN LA ESPAÑA DEL SigLO XXI}

Con respecto a la presunción Estado ladrón o Fisco usurpador, una investigación del Instituto de Estudios Fiscales sobre las opiniones y actitudes fiscales de los contribuyentes ha puesto de manifiesto que un $30 \%$ de la población justificaría el fraude fiscal (ilustración 2); de los cuales un 22\% lo haría por circunstancias de la vida personal o empresarial; y, lo que es más preocupante, un $8 \%$ lo haría porque entiende que el fraude es una cuestión consustancial a los impuestos y que es una forma de equilibrarlos, un problema estructural del sistema impositivo español. En cuanto a las causas del fraude fiscal, un 31,7\% considera que los que más defraudan están impunes; un 25,8\% que existe falta de hon radez y conciencia cívica; un 14,9\% que la lucha contra el fraude fiscal no es eficaz; un $14,4 \%$ que los actuales impues-

43 Cazorla Prieto, L.M. (introd.), Hacienda y Derecho (fragmentos), Centro de Estudios Políticos y Constitucionales, Madrid, 2015, pp. 18-20.

44 Añoveros, J., "Un jurista: Fernando Sainz de Bujanda», en Fernando Sainz de Bujanda Fundador de los estudios de Derecho Financiero y Tributario (177-187). Servicio de publicaciones. Facultad de Derecho Universidad Complutense de Madrid, Madrid, 2003, p. 178. 


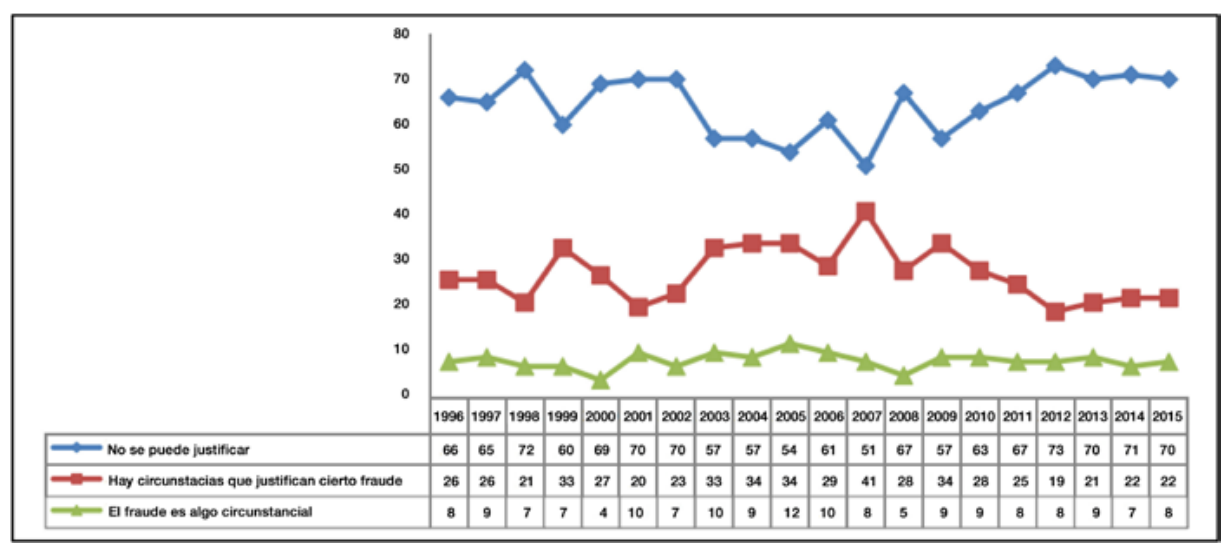

Ilustración 2. Evolución de las opiniones justificativas del fraude fiscal (1995-2015).

Fuente: Opiniones y actitudes fiscales de los españoles en 2015,

Instituto de Estudios Fiscales (IEF), p. 42.

tos son excesivos; un $6,5 \%$ que a veces hace falta trampear para salir adelante; $y$ un $5,6 \%$ que los servicios y prestaciones no se adecúan a lo que se paga ${ }^{45}$.

En el análisis del fraude fiscal desde la educación cívico-tributaria, no puede dejarse de lado la doble perspectiva que presenta, como ya hemos indicado, el fenómeno financiero de las Administraciones públicas: el ingreso y el gasto. Como muy bien destacó el profesor Rodríguez Bereijo, la unidad esencial del fenómeno financiero supone la unión inescindible entre el ingreso y el gasto público, la cual viene dada por un criterio teleológico: se ingresa para gastar ${ }^{46}$, lo que explica que la Constitución no solo se ocupe de los principios rectores de la justicia en el ingreso público, sino que también lo haga respecto del gasto, estableciendo en el artículo 31.2 que «el gasto público realizará una asignación equitativa de los recursos públicos, y su programación y ejecución responderán a los criterios de eficiencia y economía». A esa unidad teleológica entre ingreso y gasto poco ayuda que anide entre la población de modo generalizado la percepción de un Estado ladrón o Fisco usurpador, siendo responsabilidad de los poderes públicos, como destacara Sainz de Bujanda, erradicar tal percepción, lo que se logrará administrando con honestidad y probidad los recursos tributarios que se hayan obtenido de la colectividad.

Con vistas a una administración de tal carácter de los recursos tributarios, es menester, como ya hemos indicado, evitar aquellos gastos que se realizan para dar

45 El estudio a que hago referencia del Instituto de Estudios Fiscales (2016, pp. 29-42) se denomina Opiniones y actitudes fiscales de los españoles en 2015, y se encuentra disponible en https:// bit.ly/2Nr50hP.

${ }^{46}$ Rodríguez Bereijo, A., Introducción al estudio del Derecho Financiero, Instituto de Estudios Fiscales, Madrid, 1976, p. 72. 
un beneficio no fundado en criterios de justicia distributiva a determinados grupos de personas, y no a la colectividad en general -tal sería el caso, por ejemplo, de las remuneraciones a personal en términos que no se corresponden con los habituales del mercado o, en su grado máximo, cuando sus cuantías no se basan en módulos legales ni en limitaciones previamente establecidas-; o incluso, los que suponen la entrega total del producto de los impuestos, mediante el traspaso de fondos a determinadas personas o entidades vía subvenciones, cuya concesión responde más a la labor de grupos de presión que a la necesidad de atender ciertas necesidades colectivas, lo cual hace surgir una vigorosa oposición del contribuyente, por la falta de cumplimento de los principios que estructuran la gestión del Presupuesto del Estado ${ }^{47}$.

No en vano, el barómetro publicado por el Centro de Investigaciones Sociológicas (CIS), de julio de 2018, ha evidenciado que el segundo mayor problema de España, según los ciudadanos, es la corrupción y el fraude (38,5\%), al mismo tiempo que es considerado como el quinto que más les afecta $(11,2 \%)^{48}$, lo cual pone de manifiesto, a la vista también de los diferentes y numerosos casos de corrupción, prueba de una cuestionable gestión de lo público, que el Estado tampoco ha predicado con el ejemplo para generar confianza en la ciudadanía y eliminar de raíz la presunción Estado ladrón o Fisco usurpador. También resulta preocupante la cantidad de dinero de los Presupuestos Generales del Estado que se emplea para el pago de los intereses de la Deuda pública adquirida durante los años de la crisis económica y financiera, que el pasado año alcanzaría previsiblemente la cifra de 250000 millones de euros, un $25 \%$ del PIB $^{49}$, lo cual evidenciaría la renuncia por parte del Estado a hacer efectivo el mandato presente en el citado artículo 31 de nuestra

47 Sainz de Bujanda, F., op. cit., p. 127. Si bien Sainz de Bujanda no especifica concretamente a qué gastos públicos se refiere cuando habla de esta gestión inadecuada de los recursos públicos, podemos intuir que piensa en ciertas decisiones del Estado que, lejos de cumplir el mandato constitucional de proteger el interés general, se limitan a favorecer los intereses de un sector determinado. Así, podemos ver numerosos ejemplos de normas jurídicas que, bajo la generación en la sociedad de la ilusión de que se pretende proteger cuestiones que parecen propias del interés general, como puede ser el medioambiente, introducen ventajas fiscales que en realidad pretenden beneficiar, por ejemplo, a un determinado sector económico o grupo empresarial; una práctica que no solo es cuestionable desde un punto de vista jurídico y ético, sino que, aun peor, genera un clima de desconfianza de la ciudadanía hacia el Estado en cuanto a la gestión de lo público, que alienta con más fuerza que nunca la presunción Estado ladrón. Un ejemplo de ello puede ser la introducción en las leyes de presupuestos de la Comunidad Autónoma de Canarias de los ańos 2004 a 2008 del tipo reducido del 2\% a la importación y entrega de vehículos híbridos, que supuso un incentivo fiscal para la comercialización de estos vehículos llamados «ecológicos», con consecuencias económicas muy positivas para los sectores que los introdujeron en el mercado canario en este periodo, lo cual debe ser analizado con atención para detectar si dicha medida benefició en especial a algún grupo o empresa determinada, poniendo a los productos de la misma en ventaja competitiva y reduciendo sus precios vía reducir la carga tributaria para modelos concretos y ofertados por aquel entonces por un único importador.

48 Datos obtenidos del Centro de Investigaciones Sociológicas (CIS) (julio de 2018, pp. 3-4), Estudio n. ${ }^{\circ}$ 3219, disponible en https://bit.ly/2INVEbl.

49 Dato extraído del artículo del diario ElMundo titulado «Los intereses de la deuda cuestan ya 250000 millones a España desde el inicio de la crisis», a partir de la Ejecución Presupuestaria de la Intervención General del Estado, publicado el 3 de abril de 2017. Disponible en https://bit.ly/2nU2Jyj. 
Constitución, en el sentido de que el instrumento normal, ordinario y preferente de financiación del gasto público ha de ser el tributo y no otras vías, como la Deuda pública; una cuestión que, como veremos, ha sido profundamente criticada por la doctrina tributaria más afamada ${ }^{50}$.

No pretendemos justificar de ninguna manera el fraude fiscal con estas pruebas de cuestionable gestión de lo colectivo por parte del Estado, pero sí pretendemos llamar la atención de lo que expresaba Sainz de Bujanda y que volvemos a reproducir aquí: «el método educativo por excelencia es la probidad en el manejo del producto fiscal $\aleph^{51}$. En palabras de Durán-Sindreu Buxadé: «Es obvio que una política de educación tributaria sin un comportamiento ético de la Administración es y será ineficiente $\rangle^{52}$. En suma, no podemos pedirle a la ciudadanía que cumpla con sus obligaciones fiscales si, mientras tanto, es testigo de las sospechas de prácticas de corrupción y gestión ineficaz en el seno de la Administración Pública.

En cuanto a la presunción contribuyente defraudador, si bien podemos decir que está mucho más oculta, no cabe duda de que sigue existiendo, como se demuestra, aunque sea de manera vedada, en la incredulidad sistemática de la Administración Tributaria sobre las declaraciones de los ciudadanos como contribuyentes.

La Asociación Española de Asesores Fiscales (AEDAF) elaboró un documento de trabajo, en el año 2013, denominado «Malos tiempos para la seguridad jurídica de los contribuyentes", en el que denunciaba que, con las normas tributarias de urgencia producidas por el Gobierno (se refería, concretamente, a la Ley $7 / 2012$, de prevención y lucha contra el fraude ${ }^{53}$ ), con el único objetivo de aumentar la recaudación, la Administración Tributaria estaba tratando al contribuyente como un defraudador potencial. Criticaba, además, que el ciudadano se encontraba en una situación de indefensión a la hora de confrontar o resolver los conflictos generados con la Administración y concluía afirmando que, si bien era plenamente consciente del fraude fiscal existente en España y de la necesidad de combatirlo, éste no podía servir como excusa para la pérdida de derechos y garantías por parte

50 Como sabemos, durante los ańos de la crisis económica, ante la falta de ingresos para sostener los gastos públicos para el mantenimiento de los servicios públicos, el Estado recurrió sobre todo a la suscripción de deuda pública, en lugar de acudir a los tributos, la vía que nuestra Constitución marca, y así lo ha entendido también la mayoría de la doctrina, como preferente para el sostenimiento del gasto público. En este hecho, que puede parecer irrelevante, podemos detectar, como ya hemos dicho, el miedo de los políticos a la hora de recurrir a la subida de impuestos en situaciones como la descrita, por las desastrosas consecuencias que tendría esta decisión desde un punto de vista electoral, sin tener en cuenta los efectos, para nada desdeñables, de acudir al endeudamiento del Estado; una cuestión que, finalmente, acabará recayendo en los contribuyentes, no solo actuales, sino también futuros. Se demuestra, pues, la paradoja del Estado denostador de lo tributario.

${ }^{51}$ Véase cit. 18.

52 Durán-Sindreu Buxadé, A., «Fraude Fiscal y Educación Tributaria en España», Revista Derecho \& Sociedad (207-214), n. ${ }^{\circ}$ 43, 2014, p. 213.

${ }^{53}$ Ley $7 / 2012$, de 29 de octubre, de modificación de la normativa tributaria y presupuestaria y de adecuación de la normativa financiera para la intensificación de las actuaciones en la prevención y lucha contra el fraude (BOE núm. 261, de 30 de octubre de 2012). 
de los contribuyentes ${ }^{54}$. Además, son numerosas las denuncias públicas que realizan diversos organismos, con el fin de evidenciar la actitud desconfiada de la Administración para con los contribuyentes, como, por ejemplo, la que realizó en el año 2015 Pilar Otero, presidenta del Colegio de Gestores Administrativos de Galicia y, en la actualidad, vicepresidenta segunda del Consejo General de Gestores Administrativos de España, que en una entrevista al diario La Opinión de A Coruña sentenció que «Al ciudadano se le considera un defraudador en potencia y se obliga a demostrar su inocencia $\$ 5$.

En paralelo y, curiosamente, coincidiendo con la realización del presente trabajo, un grupo de más de treinta catedráticos de Derecho Financiero, entre los que cabe citar a Álvaro Rodríguez Bereijo, José María Martín Delgado, Juan Martín Queralt, José Manuel Tejerizo, Fernando Pérez-Royo o Matías Cortés, entre otros, han hecho pública una declaración que mucho tiene que ver con la materia que venimos tratando. La -como han titulado sus firmantes-Declaración de Granada denuncia que los esfuerzos de la Administración Tributaria para luchar contra el fraude fiscal no justifican en ningún caso la preterición de los principios de justicia tributaria, así como también destaca que «el afán recaudatorio se ha convertido en el único objetivo del comportamiento de los órganos tributarios, con olvido de los derechos y garantías individuales ${ }^{56}$. Como una sumaria muestra de ello, los firmantes de la citada Declaración ponen de manifiesto numerosos ejemplos -algunos de ellos analizados en el presente trabajo, como los peligros del endeudamiento público o el empleo del gasto público para satisfacer intereses individuales y no necesidades colectivas- que evidencian la quiebra de los principios de legalidad, de igualdad, de seguridad jurídica, de solidaridad y de justicia financiera en la actuación de las Administraciones Públicas. Específicamente en este apartado del trabajo, en el que tratamos de evidenciar la pervivencia de la presunción contribuyente defraudador por parte del Fisco, conviene destacar un fragmento literal de esta Declaración, en el marco de la quiebra del principio de legalidad, que sirva para ratificar definitivamente nuestros planteamientos, poniendo el foco en la autoridad académica de quienes la refrendan:

... frente al principio que garantiza la presunción de inocencia, parece haberse dado cálida acogida en las dependencias administrativas a la presunción de culpabilidad. El problema es muy grave, y se acentúa cuando, como sucede actualmente, el Legislador ha convertido al contribuyente en una especie de administrador vicario, lo que le obliga a cumplir con unas obligaciones materiales y unos deberes formales que originariamente deben ser propios de la Administración Tributaria.

${ }^{4}$ El artículo a que hago referencia es autoría de la Asociación Española de Asesores Fiscales (AEDAF) y se denomina Malos tiempos para la seguridad jurídica de los contribuyentes, $17 \mathrm{de}$ junio 2013. Disponible en https://bit.ly/2NXmcsw.

55 Fragmento extraído de la entrevista a Pilar Otero en La Opinión de A Coruña publicada el 21 de junio de 2015. Disponible en https://bit.ly/2wVyfiN.

56 Véase cit. 13. 
En esta situación, el contribuyente solo siente la cercanía de la Administración cuando se ve sancionado por haber cumplido mal, a juicio de ésta, con las obligaciones y los deberes a que está llamado. Hemos llegado asi a una Administración que solo realiza funciones de control y castigo ${ }^{57}$.

Sin duda, como destaca también la Declaración de Granada, debemos seguir luchando para acabar con el fraude fiscal, que tiene unas consecuencias desastrosas tanto para nuestra sociedad como para nuestra economía, pero eso no debe pasar, en ningún caso, por presumir que los contribuyentes son, en general, defraudadores. Hay contribuyentes que defraudan incumpliendo sus obligaciones fiscales, pero, sin duda, hay muchísimos más contribuyentes que pagan sus impuestos con la responsabilidad moral que debería caracterizar a todo ciudadano de cualquier Estado democrático que se precie. En esta línea, volvemos a reproducir la enseñanza de Sainz de Bujanda, que debería regir la actuación de las Administraciones Públicas, más allá de su afán recaudatorio o de sus funciones coercitivas: «La educación tributaria aparece como el más potente y eficaz instrumento de lucha contra el fraude. Un contribuyente educado es un contribuyente que no defrauda ${ }^{58}$.

\section{LA NECESIDAD DE UNA EDUCACIÓN CÍVICO-TRIBUTARIA DE SIGNO SOCIAL}

Hasta ahora hemos realizado un análisis acerca de algunos de los problemas educativos de nuestro país en relación con el fenómeno tributario, a través del pensamiento de Sainz de Bujanda; hemos tratado de constatar que su dialéctica de las presunciones sigue vigente en la Espańa del siglo xxi y hemos concluido que la solución pasa por la implantación decidida de la educación cívico-tributaria en la sociedad española. En el presente apartado, consideramos que es imprescindible ahondar en el tema central de este trabajo, para fundamentar por qué es tan necesaria la tantas veces reclamada educación cívico-tributaria, analizando la problemática de nuestro sistema tributario en relación con la técnica legislativa, la lucha contra el fraude fiscal o los programas de cumplimiento voluntario, entre otras cuestiones, como parte de una estrategia general de pedagogía fiscal para la ciudadanía.

57 Rodríguez Bereijo, A., Martín Delgado, J.A., Martín Queralt, J., Tejerizo, J.M., Pérez-Royo, F., Cortés, M., et al., op. cit., p. 24.

58 Sainz de Bujanda, F., op. cit., p. 105. 


\subsection{LA MEJORA DE LA TÉCNICA LEGISLATIVA PARA LA PRACTICABILIDAD DE LAS NORMAS TRIBUTARIAS}

Antes de abordar las bondades que ofrece la educación cívico-tributaria para acabar definitivamente con el fraude fiscal, resulta fundamental que hagamos referencia a un problema que también podemos encontrar en el marco del Derecho Tributario y que es crucial mejorar para lograr los fines de justicia fiscal; nos referimos, concretamente, a la técnica legislativa, es decir, la forma de elaboración y redacción de las normas jurídicas en materia tributaria y sus efectos en relación con la ciudadanía que es destinataria de éstas.

En primer lugar, debemos tener claro que el Derecho Financiero, tanto en el ámbito del Derecho de los gastos públicos como en el del Derecho de los ingresos públicos, es una disciplina compleja. Ello es así debido a la gran cantidad de conceptos jurídicos que maneja la disciplina, además de su estrecha relación con otras disciplinas científicas (no solo jurídicas, sino también económicas) que se deben controlar para su comprensión integral. De hecho, el profesor Sainz de Bujanda advierte que uno de los principales peligros a los que se enfrenta el jurista a la hora de defender los valores que encarna nuestro ordenamiento jurídico es la preeminencia de la técnica en el ámbito de la Hacienda Pública. «El daño surge cuando con la técnica se pretende sustituir al Derecho. La técnica es ineludible en la vida financiera moderna, pero su desarrollo y perfeccionamiento no pueden producirse en modo alguno a expensas de los valores jurídicos $\rangle^{59}$.

Es necesario tomar conciencia de la presencia, en numerosas normas jurídicas de la parte especial del Derecho Tributario, de un glosario jurídico tributario que acompaña a la norma y que hace prácticamente imposible de comprender e interpretar la misma por parte de la ciudadanía que está obligada a cumplirla ${ }^{60}$, motivo por el cual no nos debería extrañar la aparición de una gran cantidad de asesorías fiscales (que no encontramos en otras disciplinas jurídicas) para desentrañar el contenido de las normas y así poder aplicarlas, máxime en un contexto en el que el contribuyente debe aplicar la norma por sí mismo, en el marco de los sistemas de autoliquidación. De esta forma, se establece una excepción a lo establecido en el artículo 12 de la Ley General Tributaria ${ }^{61}$, puesto que primará en la interpretación de las normas el sentido jurídico (y no el usual) de los términos normativos.

A este aspecto que estamos abordando se refiere también de forma bastante explícita la Declaración de Granada, a la que ya nos hemos referido, en el ámbito de la quiebra del principio de legalidad en que incurre la Administración Tributaria, cuando expresa que

59 Sainz de Bujanda, F., op. cit., p. 29.

${ }^{60}$ Podemos encontrar numerosos ejemplos de esta cuestión en las reformas más recientes de la normativa tributaria, por ejemplo, en el ámbito de los delitos fiscales o la prescripción tributaria.

${ }^{61}$ Ley 58/2003, de 17 de diciembre, General Tributaria (BOE núm. 302, de 18 de diciembre de 2003). 
... el legislador usa en demasiadas ocasiones expresiones difícilmente comprensibles, permanentes remisiones normativas y otras fórmulas similares que hacen poco menos que imposible no ya la interpretación de los textos legales o reglamentarios, sino su propia comprensión, incluso por parte de los especialistas en la materia. De ello se deriva una ulterior consecuencia indeseable, y es que convierte a la DGT en una especie de oráculo que viene a explicar a todos (Administración, contribuyentes y Tribunales) la verdad revelada contenida en la norma objeto de interpretación ${ }^{62}$.

En el estudio del principio de transparencia en materia de la imposición, Fritz Neumark se refiere a la ininteligibilidad y oscuridad de las normas jurídico-tributarias, demandando la reducción de las reglamentaciones especiales, a través de la simplificación fiscal. Asimismo, critica que existe un elevado número de impuestos con una naturaleza muy compleja, solo entendible para un número ínfimo de contribuyentes, debido a la difícil formulación de las normas y a la existencia de formularios de las declaraciones tributarias muy extensos y prácticamente incomprensibles ${ }^{63}$. Y finalmente, Neumark concluye que «Una repulsa incondicional merecen [...] las violaciones del postulado de transparencia que se manifiestan en disposiciones jurídicas oscuras (imprecisas) que favorezcan la arbitrariedad de la Administración oly el fraude fiscal de los contribuyentes" ${ }^{64}$.

Esta cuestión entronca directamente con otra a la que se ha prestado muy poco interés por parte de los juristas, que se han centrado más en cuestiones de naturaleza formal de las normas jurídicas, y no de los condicionantes de la realidad social para su ejecución ${ }^{65}$ : nos referimos a la llamada practicabilidad de las normas tributarias, que ha sido definido por Neumark como:

El postulado de que se configure la Política Fiscal, en sus principios generales y en sus particularidades, de manera que sus medidas y los objetivos que con ellas se persiguen satisfagan la comprensión intelectual y las tendencias políticas del contribuyente medio (tipico), por una parte, y las atribuciones institucionales y materiales de los órganos de exacción, recaudación y control, por otra, resultando así eficazmente aplicables y practicables ${ }^{66}$.

Por tanto, debemos rescatar un paso previo y complementario en la implantación de la educación cívico-tributaria en nuestras sociedades: la mejora de la técnica legislativa, para acabar con los aspectos oscuros o ininteligibles de los textos normativos, con el fin de facilitar la practicabilidad de las normas tributarias y, en

${ }^{62}$ Rodríguez Bereijo, A., Martín Delgado, J.A., Martín Queralt, J., Tejerizo, J.M., Pérez-Royo, F., Cortés, M., et al., op. cit., p. 23. Cuando menciona la DGT se refiere a la Dirección General de Tributos.

${ }^{63}$ Neumark, F., Principios de la Imposición, Instituto de Estudios Fiscales Ministerio de Hacienda, Madrid, 1974, pp. 416-420.

${ }^{64}$ Neumark, F., op. cit., p. 423. La cursiva es nuestra.

${ }^{65}$ Génova Galván, A., «La practicabilidad de las normas tributarias», Revista de Hacienda Canaria, n.o 42, 2016, pp. 93-105.

${ }^{66}$ Neumark, F., op. cit., p. 424. La cursiva es nuestra. 
suma, para evitar la arbitrariedad de la Administración y el fraude fiscal de los contribuyentes. En conclusión, no solo la ciudadanía debe acercarse al Derecho, sino que el Derecho debe ajustarse lo más posible, bajo el principio de transparencia en la imposición, a la ciudadanía que tiene el deber de cumplirlo e incluso aplicar por sí misma, a través de la autoliquidación de las obligaciones tributarias.

Del mismo modo, complementariamente, y con esto entroncamos con el siguiente apartado, el Estado tiene el deber de educar a la ciudadanía para la comprensión de los propios conceptos tributarios utilizados habitualmente en las normas jurídicas. Ello lo explica muy bien, de nuevo, el profesor Sainz de Bujanda al comentar que "Cuanto más amplio sea el núcleo de personas que en el seno de la sociedad posean conocimientos rigurosos de Derecho financiero, más difícil será que la vida tributaria discurra por cauces irregulares» ${ }^{67}$.

\subsection{LA LUCHA CONTRA EL FRAUDE FISCAL: ¿COERCIÓN O EDUCACIÓN?}

Antes de comenzar su estudio acerca de la educación tributaria en España, Sainz de Bujanda se plantea dos posibles vías para luchar contra el fraude: la vía educativa y la vía positiva. Entiende que, si lo que queremos es combatir el fraude a la par que elevar la responsabilidad moral del contribuyente, debemos usar métodos pedagógicos, escogiendo la primera vía. Si, de lo contrario, lo que pretendemos es únicamente que la falta de ética tributaria no provoque un déficit de recaudación, sin ánimo de mejorar al contribuyente, debemos acudir a procedimientos técnicos o psicológicos decantándonos por la vía positiva ${ }^{68}$. Bajo su visión, en España prevalece la segunda, pero expresa que "La educación tributaria y la lucha contra el fraude son tareas que el Estado ha de cumplir simultáneamente, con el apoyo de conocimientos que la Psicología le brinda sobre el modo de ser del contribuyente medio, y con el aliento que la Ética y la Política le procuren para definir las metas ideales a las que ambas misiones han de dirigirse» ${ }^{69}$.

Por tanto, podemos decir que no se trata de elegir entre educar al contribuyente o perseguirlo para que cumpla; ambas actividades no son excluyentes entre sí y el Estado debe complementarlas para poder lograr un mayor grado de cumplimiento fiscal, a la vez que mejora la responsabilidad moral del contribuyente (en este sentido, en el próximo apartado analizaremos el enfoque del palo y la zanahoria). Dicho de otro modo y siguiendo a Sainz de Bujanda: si empleamos todos los recursos de la lucha contra el fraude en vencer al contribuyente mediante métodos coercitivos, en lugar de a persuadirle a través de un cambio de actitud con respecto

${ }^{67}$ Sainz de Bujanda, F., op. cit., pp. 135-136. En este punto, cuando Sainz de Bujanda se refiere a que la vida tributaria transcurra por cauces regulares, entendemos que hace alusión a este deber, tanto por parte de la Administración Tributaria, evitando la arbitrariedad en sus decisiones y actos, como por parte del contribuyente, evitando el fraude fiscal.

68 Sainz de Bujanda, F., op. cit., pp. 153.

69 Sainz de Bujanda, F., op. cit., p. 229. La cursiva es nuestra. 
al cumplimiento de sus obligaciones tributarias, no nos debe extrañar que éste no colabore y que prefiera eludir o contrarrestar las pretensiones del Fisco con las técnicas que considere oportunas ${ }^{70}$.

Durán-Sindreu Buxadé entiende que es necesario un replanteamiento de la política educativa en materia fiscal, así como también destaca que no es de gran ayuda la «tozudez de la Administración en vivir al margen de la realidad convencida de que la vía adecuada para atajar el fraude es la coercitiva», la cual lo único que genera es desconfianza por parte de los contribuyentes, que, como hemos señalado, tampoco conocen el complejo sistema tributario y que, al no comprenderlo, consideran que pagan muchos impuestos y que los instrumentos de lucha contra el fraude fiscal son insuficientes ${ }^{71}$.

$\mathrm{Al}$ referirse Pont Mestres al procedimiento inspector, considera que la educación tributaria debe ser un valor instrumental del imperio de la Ley, que sería el objetivo principal en el desarrollo de esta actividad. Expresaba el entonces catedrático de Hacienda Pública y Derecho Tributario de la Universidad Central de Barcelona que la Administración Tributaria debe procurar la comprensión del ciudadano del complejo sistema tributario, pero siendo tratado, no como un potencial defraudador, sino como una persona normal que realiza actividades por las que debe pagar tributos, en una relación basada en la colaboración y comprensión recíproca, poniendo el foco, pues, en la responsabilidad moral del contribuyente, a través de la educación ${ }^{72}$. A ello nos referiremos más adelante, cuando hagamos referencia a algunas experiencias que se han implantado, por ejemplo, en la Comunidad Foral de Navarra, donde cada vez con más intensidad la Administración Tributaria ha pasado de basar su actuación en la represión y fiscalización a la puesta en marcha de mecanismos a través de los cuales se incentiva al contribuyente a cumplir voluntaria y espontáneamente sus obligaciones tributarias, mediante la puesta en marcha en sus planes de lucha contra el fraude fiscal de programas específicos dedicados a la educación cívico-tributaria.

Por contra, Martínez Álvarez y Miquel Burgos destacan que el fin primordial de la lucha contra el fraude fiscal es el aumento de la recaudación como paso previo a la redistribución y la sostenibilidad del Estado de Bienestar. Consideran que el primer paso en esa lucha pasa por incrementar las sanciones de los defraudadores y, al mismo tiempo, realizar un mayor número de inspecciones fiscales; ya en un segundo plano, se refieren a la sensibilización fiscal de los contribuyentes para indicar que es necesaria una nueva estrategia comunicativa por parte de la Agencia Tributaria $^{73}$. Este planteamiento, al mismo tiempo que valora la educación fiscal para combatir el fraude fiscal, la coloca en una posición secundaria, pues ambos

70 Sainz de Bujanda, F., op. cit., p. 231.

71 Durán-Sindreu Buxadé, A., op. cit., pp. 213-214.

72 Pont Mestres, M., Estudios sobre temas tributarios actuales, Universidad de Barcelona, Barcelona, 1985, pp. 421-423.

73 Martínez Álvarez, J.A. y Miquel Burgos, A.B., «Instrumentos clave en la lucha contra el fraude fiscal: la importancia de la educación fiscal», Crónica Tributaria, n. ${ }^{\circ} 146,2013$, pp. 179-192. 
autores entienden que el objetivo primordial de la Administración -como critica la citada Declaración de Granada - es la recaudación y no la mejora de la cualidad de los ciudadanos como contribuyentes, haciendo especial hincapié en su responsabilidad moral o en su conciencia fiscal; renunciando pues a esa mejora cualitativa, centran la lucha en medidas coercitivas para después limitar la educación fiscal a un simple cambio en la estrategia comunicativa, como si - una vez más- de una cuestión de marketing se tratara, en lugar de a un proceso de formación continua de la ciudadanía, especialmente de la población más joven, con el fin de que se corresponsabilice en la gestión de los recursos públicos, conozca el destino de sus tributos y cumpla con sus obligaciones tributarias.

En definitiva, considero, en la línea de Sainz de Bujanda, que la herramienta más importante para luchar contra el fraude fiscal es la educación cívico-tributaria o educación fiscal; las medidas coercitivas son, sin duda, necesarias para castigar a quienes defraudan gravemente al Fisco, incumpliendo normas jurídicas obligatorias, pero esas medidas no van a prevenir el fraude futuro; a lo sumo, simplemente harán que se recupere una parte del dinero efectivamente defraudado, para aumentar la recaudación. La lucha contra el fraude fiscal debe consistir en un conjunto de acciones multidisciplinares y transversales que pongan el foco en la conciencia fiscal del contribuyente, en la profundización de su responsabilidad moral para el cumplimiento de su obligación de contribuir al sostenimiento de los gastos públicos, pero no como una mera estrategia comunicativa, sino como una apuesta decidida y continuada en el tiempo, dotada de recursos suficientes y, sobre todo, basada en la convicción de que podemos mejorar como sociedad mediante la vía educativa, para que la ciudadanía pague sus tributos con conciencia de que ello reportará una mejora de la calidad de los servicios públicos, del Estado de Bienestar que nos hemos dado y, sobre todo, la redistribución de la riqueza.

Para terminar este apartado, quisiera reproducir una importante cita del profesor Sainz de Bujanda:

Sólo un Estado que educa, al tiempo que exige, puede, en definitiva, hacer soportable la carga tributaria a la colectividad. Para un contribuyente educado, el tributo es un noble y honroso sacrificio; para un contribuyente sin educar, es una expoliación abusiva ${ }^{74}$.

\subsection{LOS PROGRAMAS DE CUMPLIMIENTO TRIBUTARIO VOLUNTARIO Y COOPERATIVO EN} LA LUCHA CONTRA EL FRAUDE FISCAL

Una vez que nos hemos inclinado en el sentido de que la posición del Estado en la lucha para acabar con el fraude fiscal pasa fundamentalmente por la educación (y no tanto por la coacción), no podemos pasar por alto una cuestión que está

74 Sainz de Bujanda, F., op. cit., p. 231. 
teniendo especial relevancia en los sistemas tributarios de España y el mundo: los programas de cumplimiento tributario voluntario y cooperativo; una nueva vertiente promovida por la Organización para la Cooperación y el Desarrollo Económico (en adelante OCDE), que se está poniendo en marcha cada vez con mayor frecuencia en numerosos Estados.

Simbólicamente, podríamos analizar estos nuevos programas de cumplimiento, mediante el enfoque del palo y la zanahoria, que debiera regir la actuación de la Administración para adaptarse al tipo de contribuyente. Como explica Soto Bernabéu, la zanahoria quedaría representada por los incentivos propuestos en los programas de cumplimento voluntario, que pueden consistir en reducciones de la deuda o intereses de demora; por su parte, el palo simbolizaría las medidas coercitivas o punitivas a las que no debe renunciar la Administración, tanto con una finalidad disuasoria como sancionadora, ante los posibles incumplimientos del contribuyente ${ }^{75}$. Este enfoque está presente, de alguna manera, en la visión de Sainz de Bujanda que hemos tratado de dilucidar en este trabajo, en el sentido de que la vía educativa y la positiva son, a su modo de ver, complementarias para la lucha contra el fraude fiscal.

En cualquier caso, debemos tener en cuenta que, como nos dice Soto Bernabéu, «no existe un único tipo de contribuyente» ${ }^{76}$; existen múltiples circunstancias que inciden en el cumplimiento o no de sus obligaciones tributarias, por lo que debemos analizar los motivos que incitan a una parte de la ciudadanía a incumplir sus obligaciones para con el Fisco, algunas de las cuales ya hemos recogido en este trabajo, como la falta de confianza en el sistema, la complejidad de la normativa, la visión de que el sistema es injusto, cuestiones morales o éticas, el papel del Estado como denostador de lo tributario, etc.

Así, el cumplimiento voluntario por parte de los contribuyentes, no solo debe ser el objetivo de cualquier Administración Tributaria que se precie, sino también la mejor herramienta para recaudar los ingresos tributarios al menor coste posi$\mathrm{ble}^{77}$. Un contribuyente puede cumplir sus obligaciones en el periodo voluntario o de forma extemporánea, pero debemos considerar que el cumplimiento es voluntario cuando la Administración no ha ejercitado ninguna potestad para exigir el pago de las deudas tributarias, lo cual comporta no incurrir en costes administrativos ${ }^{78}$.

75 Soto Bernabéu, L., «Los programas de cumplimiento voluntario como medidas de estímulo al cumplimiento extemporáneo de las obligaciones tributarias», Nueva Fiscalidad (195-213), n. ${ }^{\circ} 1,2018$, p. 197. Este enfoque descansa, según la autora, en lo que Ayres y Braithwaite han calificado como responsive regulation, mediante una filosofía quid pro quo. Cfr. Ayres, I. y Braithwaite, J.: Responsive regulation, New York: Oxford University Press, Inc., 1992, pp. 4-7.

76 Soto Bernabéu, L., op. cit., p. 199.

77 Soto Bernabéu, L., op. cit., p. 198.

${ }^{78}$ El único coste que ese cumplimiento extemporáneo comporta es de naturaleza financiera, que queda cubierto suficientemente mediante el interés de demora; por su parte, con respecto a los recargos en este periodo, la finalidad que persiguen no es de carácter represivo sino, precisamente, incentivar el cumplimiento espontáneo por el contribuyente, aunque sea fuera de plazo, como exponemos en el texto. 
De esta forma, la OCDE ha promovido la creación de programas de cumplimiento voluntario, que pueden ser generales o especiales. En nuestra legislación, podemos encontrar un ejemplo de programa de cumplimiento voluntario general en el artículo 27 de la Ley General Tributaria, en lo relativo al régimen de los recargos por declaración extemporánea sin requerimiento previo por la Administración, con la oportunidad permanente para que el contribuyente incumplidor regularice voluntariamente su situación, como un estímulo al cumplimiento voluntario; en cuanto a los programas especiales, han sido -y siguen siendo-objeto de polémica, como la última regulación de la declaración tributaria especial (más conocida coloquialmente como amnistía fiscal), a través del Real Decreto-Ley 12/2012, de 30 de marzo ${ }^{79}$, declarado inconstitucional por Sentencia del Tribunal Constitucional de 8 de junio de 2017.

Soto Bernabéu concluye, siguiendo la doctrina tributaria más afamada, que los programas de cumplimiento voluntario son la herramienta más apropiada para la consecución de dos objetivos: por un lado, el aumento de la recaudación de un modo más rápido y a un menor coste; $\mathrm{y}$, por otro, la mejora del cumplimiento espontáneo por parte de los contribuyentes de sus obligaciones tributarias ${ }^{80}$. Han sido numerosos los Estados que han puesto en marcha en todo el mundo programas de cumplimiento voluntario (Argentina, Bélgica, Brasil, Italia, Portugal, El Salvador, Guatemala, Turquía, etc.), pero, concretamente dentro de España, debemos destacar a la Comunidad Foral de Navarra, que ha impulsado en sus Planes de Lucha contra el Fraude Fiscal una serie de medidas en las que se incentiva el cumplimiento voluntario por parte del contribuyente, con el convencimiento de que «si se persigue conseguir que los contribuyentes cumplan de la manera más completa y puntual con sus obligaciones tributarias, la Administración ha de desplegar cuantas medidas pueda para que ese cumplimiento se realice de la manera más cómoda posible» ${ }^{81}$; lo cual demuestra que han ido calando en la Administración navarra las ideas de Sainz de Bujanda, en el sentido de que el comportamiento del Fisco para con los contribuyentes fuera menos coercitivo y más pedagógico, facilitando así el cumplimiento espontáneo de sus obligaciones tributarias; una nueva tendencia que debe estar presente en las estrategias implementadas por la Administración Tributaria, para prevenir y luchar contra el fraude fiscal.

Algunos ejemplos de las medidas incorporadas por parte de la Comunidad Foral de Navarra para fomentar el cumplimiento voluntario de los contribuyentes los podemos encontrar en uno de los apartados del Plan de Lucha contra el Fraude Fiscal 2016-2019, en el que se hace alusión a la notificación electrónica, la modificación de la potestad de representación tributaria, la potenciación del cumplimiento

79 Real Decreto-Ley 12/2012, de 30 de marzo, por el que se introducen diversas medidas tributarias y administrativas dirigidas a la reducción del déficit público (BOE núm. 78, de 31 de marzo de 2012).

${ }^{80}$ Soto Bernabéu, L., op. cit., p. 210.

${ }^{81}$ Frase extraída del Plan de Lucha contra el Fraude Fiscal 2016-2019 del Gobierno de Navarra, en su página 32. Disponible en https://bit.ly/2Qb4xix. 
de obligaciones por vía telemática, la simplificación de las obligaciones tributarias, la organización de los medios adecuados para la atención al público, entre otras.

Por otro lado, también se ha formado, bajo recomendaciones de la OCDE, un nuevo modelo de cumplimiento tributario cooperativo, en virtud del cual se postula que se debe crear una relación institucional cooperativa entre la Administración Tributaria y los contribuyentes, asumida voluntariamente por ambos bajo la confianza mutua, el diálogo, la transparencia y la búsqueda del entendimiento a través de la reciprocidad, con lo que se pretende la aplicación correcta de las leyes fiscales, para una determinación correcta de la cuantía del impuesto, mediante el respeto de los derechos de todas las partes ${ }^{82}$. Este nuevo modelo de relación entre la Administración y la ciudadanía, implantada en numerosos Estados (Irlanda, Países Bajos, Estados Unidos, Australia, entre otros), aspira a lograr el mayor índice posible de cumplimiento voluntario por parte de los contribuyentes. Calderón Carrero y Quintas Seara sintetizan a la perfección el objetivo de esta novedosa relación cooperativa: «viene a configurarse como una relación que favorece la colaboración frente a la confrontación, y se encuentra anclada más en la confianza mutua que en una dinámica relacional legal que pivota sobre un modelo de sujeción fiscal del contribuyente basado en las obligaciones legalmente establecidas» ${ }^{83}$.

Podríamos desarrollar extensamente este apartado en relación con los programas de cumplimiento tributario voluntario y cooperativo, pero únicamente era nuestro interés mostrar una tendencia actual, a nivel internacional, fundamentada en la confianza mutua entre la Administración Tributaria y los contribuyentes, que solo puede tener sentido, de una forma o de otra, mediante la implantación de una educación cívico-tributaria de signo social, que favorecerá la eficacia de estos novedosos programas puestos en marcha, como hemos visto, dentro y fuera de España.

\subsection{LA EDUCACIÓN CÍVICO-TRIBUTARIA EN EL MARCO DE UNA EDUCACIÓN EN VA- LORES DEMOCRÁTICOS}

El filósofo y sociólogo francés Edgar Morin, al reflexionar sobre la educación del futuro en un libro realizado en colaboración con la UNESCO, planteó que debíamos enseñar la democracia y el civismo, entre otras cosas porque la democracia supone al mismo tiempo la autolimitación del poder estatal con la consiguiente separación de poderes, la garantía de los derechos individuales y la protección de la vida privada. Criticaba Morin los procesos en los que se marginaba a la ciudadanía de las decisiones políticas, para ser sustituida por expertos técnicos, por lo que los ciudadanos se ven usurpados de los problemas fundamentales de la sociedad; concluyendo que todos estos factores producían el debilitamiento del civismo, la evasión

82 Calderón Carrero, J.M. y Quintas Seara, A., Cumplimiento tributario cooperativo y Buena gobernanza fiscal en la era BEPS, Editorial Aranzadi, Navarra, 2015, pp. 64-65.

${ }^{83}$ Calderón Carrero, J.M. y Quintas Seara, A., op. cit., p. 68. La cursiva es nuestra. 
y la búsqueda del refugio en la vida privada, debilitando, en suma, la democracia ${ }^{84}$. Sin duda, esto que comentaba el sociólogo en el marco de los retos educativos del vigente siglo XxI tiene mucho que ver con la educación cívico tributaria, tal y como la entendemos.

Decía Ortega y Gasset que «El problema de los españoles es un problema educativo; pero éste, a su vez, es un problema de ciencias superiores, de alta cultura ${ }^{85}$. Un reciente estudio de la Universidad Estatal de Sonora (México) ha demostrado la correlación existente entre cultura y educación tributaria, lo cual evidencia que, a pesar del endurecimiento de las sanciones legales impuestas a los defraudadores, los contribuyentes no se han concienciado de sus obligaciones tributarias, ni siquiera en los niveles de educación superior, una cuestión a la que no ayuda la complejidad de las leyes en materia fiscal, por lo que se propone la puesta en marcha de forma urgente de programas de educación fiscal para generar cultura tributaria ${ }^{86}$.

Durán-Sindreu Buxadé ha puesto de manifiesto, en el artículo a que hemos hecho referencia con anterioridad, la necesidad de implantar una educación cívico-tributaria diferente a la planteada hasta ahora: debe estar basada en principios cívicos, éticos y morales, teniendo en cuenta el pago de los impuestos como una obligación ética de la ciudadanía. En este sentido, expresa que "es imprescindible una educación basada en el deber cívico de contribuir entendido como valor, y no como obligación, y su más profunda razón de ser: la justa redistribución de la riqueza como un exponente de la solidaridad ${ }^{87}$.

No cabe duda de que el artículo 31 de nuestra Carta Magna es claro al expresar que todos tenemos el deber de contribuir al sostenimiento de los gastos públicos y que la categoría de obligación es, como ya nos dice el profesor Clavijo, en tanto que uno de los denominados legados de Sainz de Bujanda, el eje dogmático del Derecho Tributario ${ }^{88}$. Sin embargo, considero que en el marco de la educación cívico-tributaria se debe hacer hincapié también en la responsabilidad moral del contribuyente o conciencia fiscal, poniendo el foco en su deber cívico de contribuir al sostenimiento de los gastos públicos, mediante el pago de los tributos. Debemos señalar igualmente que es elemental que la ciudadanía comprenda el sistema tributario desde el valor de justicia redistributiva y de solidaridad que lo fundamenta; valores de la democracia, que deben ser fomentados, a través de los métodos educativos y pedagógicos.

${ }^{84}$ Morin, E., Los siete saberes necesarios para la educación del futuro, Paidós Studio, Barcelona, 2000, pp. 131-138.

85 Ortega y Gasset, J., "La pedagogía social como problema político», en Obras Completas, vol. I, Rev. Occ., Madrid, 1946, p. 84.

${ }^{86}$ Mendoza Shaw, F., Palomino Cano, R., Robles Encinas, J.E. y Ramírez GuarDADO, S.R., "Correlación entre cultura tributaria y educación tributaria universitaria: caso Universidad Estatal de Sonora", Revista Global de Negocios, vol. 4, n. . 1, 2016, pp. 61-76.

87 Durán-Sindreu Buxadé, A., op. cit., p. 213.

${ }^{88}$ Clavijo, F., "El legado de Sainz de Bujanda en Derecho Tributario», en Fernando Sainz de Bujanda Fundador de los estudios de Derecho Financiero y Tributario (147-156). Servicio de publicaciones. Facultad de Derecho Universidad Complutense de Madrid, Madrid, 2003, p. 148. 
La educación cívico-tributaria debe pivotar en el marco de una educación en valores democráticos, donde la ciudadanía entienda que vivir en democracia y disfrutar de los servicios públicos, como la educación o la sanidad, tiene un coste, que debe ser asumido por la colectividad, a través de un sistema impositivo justo. Si la ciudadanía toma conciencia de su condición de contribuyentes con cultura y educación tributaria, cumplirá con sus obligaciones fiscales, porque sabe que reportaría en su propio beneficio como ciudadano, pero también, como hemos comentado, impedirá o se resistirá ante cualquier ejercicio arbitrario del Derecho por parte del Estado.

En suma, no se debe fomentar la educación cívico-tributaria para que el ciudadano pague sus tributos adormecido, sino para despertar su conciencia fiscal en el marco de una educación en valores. En este sentido, Sainz de Bujanda expresaba que

No puede razonablemente postularse que los sujetos paguen los impuestos insensiblemente, como en un sueño, adormecidos por no sabemos qué engaños o ilusiones. Esa anestesia fiscal que se predica es un veneno corrosivo que destruye las raíces de los ideales tributarios. Frente a ella alzamos la voz en defensa de un robustecimiento incesante de la conciencia tributaria ${ }^{89}$.

\section{EL FRACASO EN LA IMPLANTACIÓN DE LA EDUCACIÓN CÍVICO-TRIBUTARIA EN ESPAÑA}

En el año 2003 se crea en España el Programa de Educación Cívico-Tributaria (en adelante, PECT), dependiente de la Agencia Estatal de Administración Tributaria (en adelante, AEAT), fruto de diversos estudios demoscópicos sobre el fraude fiscal realizados por el Instituto de Estudios Fiscales (en adelante, IEF), en los que se demostraba que un $73 \%$ de la población consideraba que la educación cívico-tributaria en la etapa escolar podía influir positivamente en el cumplimiento fiscal en el futuro ${ }^{90}$. El trabajo del PECT desde entonces se ha centrado fundamentalmente en realizar diversas jornadas de puertas abiertas en las delegaciones de la Agencia Tributaria y en la creación de un portal web específico sobre la educación cívico-tributaria destinado a estudiantado y profesorado ${ }^{91}$, así como el ofrecimiento de diversas charlas y formaciones específicas a los diversos sectores de la comunidad educativa. Todo ello cuenta con unas valoraciones profundamente positivas por parte del personal técnico responsable del PECT, teniendo en cuenta que los resultados solo se podrán ver a largo plazo y también los retos de continuidad del programa, como la extensión a más niveles educativos, la intensificación de la formación del

89 Sainz de Bujanda, F., op. cit., pp. 119-120. La cursiva es nuestra.

${ }_{90}$ El dato a que hago referencia fue extraído del documento de trabajo del Instituto de Estudios Fiscales (IEF) que lleva por título Opiniones y actitudes fiscales de los contribuyentes en 2004, publicado en el año 2005, p. 59. Disponible en https://bit.ly/2QeD4fK.

${ }_{91}$ Disponible en https://bit.ly/1gc11NN. 
profesorado y la renovación del material didáctico ${ }^{92}$. En cuanto al impacto en el año 2009, el PECT había alcanzado la cifra de 166589 alumnos y 13084 profesores $^{93}$.

Sin embargo, sin menospreciar el trabajo desarrollado en el marco del PECT, parece haber un vacío existencial, desde el año 2009 hasta la actualidad, en la evaluación del impacto y los resultados que el programa ofrece, para poder analizar si los retos enunciados para la continuidad del programa se han implantado efectivamente. De hecho, la socióloga y colaboradora del IEF Ruiz de Zauzu ha manifestado que el programa se encuentra congelado por la falta de apoyo institucional y de financiación para poner en marcha las importantes aspiraciones del PECT; según expresa, solo se realizan acciones dispersas en algunas provincias gracias a la labor desinteresada de los formadores ${ }^{94}$. Lo que sí parece evidente, a la vista de lo planteado, es que el programa ha fracasado en su compromiso de continuidad; que las acciones desarrolladas se demuestran a todas luces insuficientes; que falta llegar a muchos sectores de la población de una forma transversal y de forma continuada en el tiempo; así como que los recursos didácticos que ofrece el PECT están completamente desfasados (una prueba de ello es el portal web del programa), lo cual requiere una actualización integral, que permita el acercamiento de la población, especialmente de la más joven, en aras de la consecución de los importantes objetivos del PECT.

Por otro lado, en el año 2006 se crea en España, siguiendo recomendaciones del Consejo de Europa, la Educación para la Ciudadanía, una asignatura obligatoria en la Educación Primaria y Secundaria, cuyos objetivos fundamentales pasan por «favorecer el desarrollo de personas libres e íntegras a través de la consolidación de la autoestima, la dignidad personal, la libertad y la responsabilidad y la formación de futuros ciudadanos con criterio propio, respetuosos, participativos y solidarios, que conozcan sus derechos, asuman sus deberes y desarrollen hábitos cívicos para que puedan ejercer la ciudadanía de forma eficaz y responsable»"

Esta asignatura incorporaba a su currículo académico material didáctico relativo al Derecho Tributario, con apartados específicos relativos a los impuestos y la contribución de los ciudadanos, en un bloque formativo sobre las sociedades democráticas del siglo xxi. Como muestra de ello, un libro de esta asignatura para alumnado de Educación Secundaria Obligatoria (ESO) abordaba en una de sus unidades el concepto de Hacienda Pública, la relación entre el pago de los tributos y el disfrute de los servicios públicos, los principios fundamentales del sistema tributario, el concepto de impuesto y sus tipos, así como las repercusiones del fraude

${ }_{92}$ Estos datos son extraídos del documento de trabajo del Instituto de Estudios Fiscales (IEF) denominado La experiencia educativa de la Administración Tributaria Española, publicado en el año 2009. Disponible en https://bit.ly/2hVtQHz.

${ }_{93}$ Según el estudio más reciente encontrado, citado en la nota anterior.

94 Ruiz de ZAuzu, M.G., "Medidas sociales para combatir el fraude fiscal en España», Fundación Alternativas, 2014, p. 29. Disponible en https://bit.ly/2eB0XuW.

95 Real Decreto 1631/2006, de 29 de diciembre, por el que se establecen las enseñanzas mínimas correspondientes a la Educación Secundaria Obligatoria (BOE núm. 5, de 5 de enero de 2007). 
fiscal y la economía sumergida, entre otras cuestiones; con contenido teórico y práctico $^{96}$. Se procedía a incorporar, de esta forma, la educación cívico-tributaria en el marco educativo general, fomentando, al fin y al cabo, la conciencia fiscal de los contribuyentes del futuro. Sin embargo, fruto de la polémica que se generó sobre su presunto contenido ideológico, la asignatura fue eliminada con la Ley Orgánica $8 / 2013$, de 9 de diciembre, para la mejora de la calidad educativa (LOMCE) ${ }^{97}$, sin que hasta la fecha se haya sabido implantar una alternativa para seguir promoviendo la educación cívico-democrática y en Derechos Humanos, tal como recomienda el Consejo de Europa ${ }^{98}$.

No obstante, tras la eliminación de la asignatura de Educación para la Ciudadanía, se procedió a incorporar progresivamente cuestiones relativas a la educación financiera en los centros educativos, introducidas desde la Educación Primaria al currículo de otras asignaturas como Ciencias Sociales o Economía, con contenidos como el dinero, el ahorro, la empleabilidad y el espíritu emprendedor, así como las actividades y funciones de las empresas, entre otros asuntos ${ }^{99}$. De hecho, el Informe español PISA 2012 sobre competencia financiera, elaborado por el Instituto Nacional de Evaluación Educativa (INEE), dependiente del Ministerio de Educación del Gobierno de España, cita la educación cívico-tributaria en una sola ocasión en el marco del análisis de Educación para la Ciudadanía; y, sin embargo, expresa sobre la educación financiera que «la evolución de la sociedad española y su economía hace ver que ha aumentado la necesidad de formar a jóvenes y adultos en educación financiera», para después hacer referencia a la implantación de esta materia en primaria y secundaria, a través de las asignaturas de Ciencias Sociales y Economía ${ }^{100}$.

En este sentido, han sido muchas las voces críticas que han salido al paso de la incorporación de estos contenidos en el sistema educativo, a la vista del aparente abandono de la educación cívico-tributaria o fiscal en nuestro país. Una de ellas ha sido la de Rodríguez Márquez, profesor titular de Derecho Financiero y Tributario de la Universidad Complutense de Madrid y director de estudios del IEF, que mostraba su sorpresa ante el éxito de la incorporación de la educación financiera en la enseñanza (la cual sí considera necesaria) y manifiesta que no se está priorizando

96 Pérez Carrasco, J., Díaz Otero, C. y Díaz Fleitas, J.M., Jóvenes Ciudadan@s, Educación para la ciudadanía y los derechos humanos, Pearson Alhambra, Madrid, 2008, pp. 47 y 68-69.

${ }^{97} B O E$ núm. 295, de 10 de diciembre de 2013.

${ }^{98}$ Lo cual supone, según algunos autores, un grave retroceso en muchos sentidos para nuestro sistema educativo, en el que ha quedado excluida y olvidada la educación cívico-tributaria. Cfr. Muñoz Ramírez, A.: "¿Qué ha sido de Educación para la Ciudadanía con el Partido Popular?», Foro de Educación, 14 (20), Salamanca, 2016, pp. 105-128. Disponible en el siguiente enlace web: http://dx.doi.org/10.14516/fde.2016.014.020.007.

${ }_{99}$ Real Decreto 126/2014, de 28 de febrero, por el que se establece el currículo básico de la Educación Primaria (BOE núm. 52, de 1 de marzo de 2014).

${ }^{100}$ Extraído del Informe español PISA 2012 sobre competencia financiera, Instituto Nacional de Evaluación Educativa (INEE), Ministerio de Educación Gobierno de España (p. 14). Versión preliminar disponible en https://bit.ly/2wY8HkQ. 
bien en este asunto, a la par que destaca la importancia de la educación fiscal, no solo para la Agencia Tributaria, sino para el conjunto de la sociedad y el resto de poderes públicos ${ }^{101}$. Más intensas han sido las críticas de Rodolfo Rieznik, economista y vocal de la Junta Directiva de Economistas Sin Fronteras, que expresó su total rechazo a la implantación de la educación financiera en las aulas e hizo una reivindicación de una mayor educación y responsabilidad fiscal y tributaria, en detrimento de las finanzas, alertando de la sucesiva desaparición de la educación fiscal, que ya hemos analizado ${ }^{102}$. También, desde la Plataforma por la Justicia Fiscal, se alertaba recientemente sobre los efectos del desmantelamiento de la educación cívico-tributaria en los currículos de enseñanza, exigiendo la recuperación de las iniciativas del PECT y, sobre todo, la inclusión en el Pacto de Estado por la Educación del compromiso para dar cabida a la educación fiscal en los centros educativos, pues destacan que su objetivo primordial «es transmitir valores y actitudes favorables a la responsabilidad fiscal y contrarios a las conductas defraudadoras»; cuestiones que se están perdiendo ante un alarmante déficit de conciencia fiscal ${ }^{103}$.

En suma, resulta más que acreditado que el Estado se ha olvidado de la educación cívico-tributaria que intentó implantar a través del PECT y que, por tanto, ha fracasado en su misión de fomentar la conciencia fiscal de los contribuyentes para, así, conseguir un mayor grado de cumplimiento fiscal. La falta de apoyo institucional y de recursos económicos ha terminado por desterrar la educación cívico tributaria de la enseñanza en los centros educativos españoles. A la vista de lo planteado, parece que el Estado tiene otras prioridades que no pasan por mejorar la educación fiscal de los contribuyentes, lo cual coadyuvaría también a eliminar de raíz las presunciones vigentes del Estado ladrón y contribuyente defraudador, que, lógicamente, se perpetuarán en el tiempo hasta que la Administración se decida a poner en marcha iniciativas estables y continuas de educación fiscal; las incorpore decididamente al currículo de enseñanza de la educación primaria y secundaria; así como, y esto es muy importante, las dote de los recursos y apoyo institucional suficientes para que se mantengan en el tiempo. Esto no es óbice para que se mantenga una educación sobre ciertas materias financieras; sin embargo, lo que no es asumible en el marco del Estado social como Estado fiscal es la erradicación de los contenidos tributarios de los planes de estudios de quienes, ineludiblemente, mañana serán contribuyentes.

Los problemas del país relativos a la educación fiscal siguen vigentes, porque no se ha hecho lo suficiente para acabar con ellos, con la implantación decidida de

101 Artículo de opinión de Jesús Rodríguez Márquez en el diario digital Cinco Días, bajo el título «Es tiempo de educación fiscal», publicado el 28 de octubre de 2016. Disponible en https:// bit.ly/2wXE7aW.

${ }^{102}$ Artículo de opinión de Rodolfo Rieznik en eldiario.es, bajo el título «Educación financiera o educación fiscal y tributaria», publicado el 9 de junio de 2017. Disponible en https://bit.ly/2MgPJvG.

103 Artículo de opinión de José Manzanarez Núnez, miembro de la Plataforma por la Justicia Fiscal, en el diario digital infolibre, bajo el título «Educación fiscal contra pobreza y desigualdad», publicado el 29 de septiembre de 2017. Disponible en https://bit.ly/2xTetol. 
la educación cívico-tributaria, que sigue siendo, como reza el título de este trabajo, una asignatura pendiente, lo cual, sumado al nuevo rol del Estado como denostador de lo tributario, provoca un crecimiento incesante del fraude fiscal.

\section{ALGUNAS PROPUESTAS DE BUENAS PRÁCTICAS EN ESPAÑA Y EN EL MUNDO}

En el presente apartado trataremos de esbozar algunos ejemplos de dentro y fuera de España, donde se han desarrollado iniciativas que nos pueden servir de referencia para implantar-recuperar-a nivel estatal un programa de educación cívico-tributaria que, atendiendo a la realidad concreta de nuestro país, logre ser eficaz en la lucha contra el fraude fiscal. Estas propuestas deben sumarse a los diversos remedios planteados por Sainz de Bujanda, así como otros destacados en este trabajo, para acabar con la pervivencia del mecanismo de las presunciones y el papel del Estado como denostador de lo tributario.

En este sentido, la OCDE ha publicado un libro que pretende ser una guía sobre educación tributaria en el mundo y que recoge las innovadoras estrategias de veintiocho países alrededor de todo el planeta en el marco de la educación fiscal. Se plantean, en concreto, las propuestas de buenas prácticas en este ámbito de países como Bangladesh, Bután, Brasil, Burundi, Chile, Colombia, Costa Rica, El Salvador, Estonia, Guatemala, Jamaica, Kenia, Corea, El Líbano, Malasia, Mauricio, México, Mozambique, Nigeria, Perú, Ruanda, Senegal, Singapur, Sudáfrica, Turquía, Uruguay o Zambia ${ }^{104}$. En la sinopsis del libro se recoge expresamente el convencimiento de que «La Educación Cívico-Tributaria no es sólo una estrategia para recaudar más ingresos ni se centra exclusivamente en explicar por qué han de pagarse los impuestos, más bien intenta fortalecer actitudes de compromiso con el bien e interés general enfatizando el valor social del impuesto y su nexo con el gasto público» ${ }^{105}$.

Resulta profundamente instructiva la lectura de las diferentes propuestas que estos países han desarrollado en sus sociedades, con el fin de implantar decididamente una educación fiscal eficaz. A continuación, desarrollaremos algunos programas aun activos de determinados Estados que, por su proximidad cultural con España, podrían servirnos de ejemplo para su traslación adaptada a nuestro país:

a) Programa de Educación Fiscal del Servicio de Impuestos Internos de Chile ${ }^{106}$. Puesto en marcha en el año 2006, el programa desarrollado en Chile para el fomento

${ }^{104} \mathrm{OECD} /$ The International and Ibero-American Foundation for Administration and Public Policies (FIIAPP), Fomentando la cultura tributaria, el cumplimiento fiscal y la ciudadanía. Guia sobre educación tributaria en el mundo, OECD Publishing, París, 2015. Disponible completo en http://dx.doi.org/10.1787/9789264222786-es.

${ }^{105}$ OECD, op. cit., p. 13.

106 OCED, op. cit., pp. 55-62. 
de la educación fiscal se ha concretado en las siguientes tareas: un portal web educativo, una obra de teatro representada en todo el país, artículos promocionales en revistas especializadas, entrega de material didáctico en las aulas, series en la televisión nacional chilena, visitas a colegios y charlas de los funcionarios, incorporación del programa a los planes de estudios de los centros de enseñanza secundaria y superior e inclusión de un módulo de educación cívico-tributaria en la formación de los nuevos funcionarios, entre otras medidas. Especial importancia reviste el Programa de Educación Fiscal en línea (SIIEduca y Planeta SII), dirigido a docentes, padres, tutores, alumnado y comunidad en general (con diferente tratamiento en el propio portal web), para aprender sobre la materia tributaria de una forma didáctica; resulta imprescindible destacar que ambos portales web se han actualizado recientemente, para facilitar la inclusión de las redes sociales y otras tecnologías de la información en el proceso de aprendizaje, con unos resultados profundamente positivos ${ }^{107}$.

b) Programa Nacional de Educación Fiscal del Servicio de Administración Tributaria de México ${ }^{108}$. En el año 1997 nace este programa en México, que concibe la participación ciudadana como un elemento fundamental de la educación fiscal y que ha desarrollado, entre otras, las siguientes acciones: diseño de asignaturas específicas sobre fiscalidad en educación superior, inclusión de contenidos fiscales en material escolar gratuito, creación del personaje Fiscalito para formar con diversión al alumnado de educación primaria, conferencias y visitas guiadas, exposiciones y ferias culturales y la creación de un centro recreativo para jóvenes llamado Kidzania, la ciudad de los impuestos. La implantación de una asignatura específica sobre formación e información tributaria en más de medio centenar de Universidades mexicanas, así como en la educación a distancia, ha tenido especial importancia en el desarrollo de este programa, que aún tiene muchos retos por delante ${ }^{109}$.

c) Programa de Educación Fiscal de la Dirección General Impositiva de Uruguay ${ }^{110}$. Impulsado en el año 2003, la acción más novedosa propuesta por el mismo versa sobre los videojuegos sobre educación tributaria: consiste en dotar a cada niño del país de un ordenador portátil (Plan Ceibal) para utilizar en el aula de los centros de educación primaria, con diversos videojuegos sobre educación cívico-tributaria, donde se abordan temas como los derechos y obligaciones, la sociedad, el Estado y la cultura fiscal; cabe destacar que han tenido un amplio alcance en el país ${ }^{111}$. Asimismo, se puso en marcha

107 Más información en http://www.sii.cl/destacados/sii_educa/.
108 OCED: op. cit., pp. 137-143.
109 Más información en https://www.sat.gob.mx/home.
110 OCED: op. cit., pp. 199-205.
111 Destacamos esta iniciativa para contraponerla a la reciente polémica que se ha generado en torno a la decisión de la Consejería de Educación del Gobierno de Canarias a la hora de introducir en los centros educativos los llamados eSports, con videojuegos deportivos competitivos (más 
un portal web en el que la población más joven podría encontrar no solo los videojuegos, sino también información relativa al ámbito tributario ${ }^{112}$.

d) Programa de Educación Civico-Tributaria Dirección General de Tributación de Costa Rica ${ }^{113}$. Creado en el año 2010, ha iniciado acciones muy interesantes en esta materia, como la semana de cultura fiscal en el calendario escolar, los cursos de formación para docentes de primaria, secundaria, personal de la administración y cursos básicos de fiscalidad para estudiantes de contabilidad, entre otras. La propuesta más interesante de este programa es la Sala de Juegos Un tributo a mi pais, un espacio específico en el Museo del@s Niñ@s, situado en la capital de Costa Rica, donde se da cabida a más de una docena de juegos interactivos en materia fiscal, que ha tenido un impacto de casi 100000 personas entre 2010 y 2013, con el reto de poder implantar una sala de juegos como esta en cada escuela del país ${ }^{114}$.

No cabe duda, a la vista de lo expuesto en este apartado sobre buenas prácticas, que tenemos mucho margen en España para mejorar nuestro - congeladoPrograma de Educación Cívico-Tributaria: se requieren políticas más estables, actualizadas e innovadoras, que pongan el foco en la conciencia fiscal del contribuyente. Es más que probable que Espańa pueda encontrar a lo largo de estas páginas novedosas iniciativas, puestas en marcha por Estados en vias de desarrollo que, con compromiso institucional y político, han logrado sustentar en el tiempo programas de educación tributaria, donde se pone el foco en la conciencia fiscal de los contribuyentes, como recomendamos en este trabajo de investigación.

Sin embargo, a decir verdad, también podemos encontrar en España algunas iniciativas que nos demuestran que, con compromiso institucional y político, se puede intentar implantar la educación cívico-tributaria o educación fiscal. A modo de ejemplo, podemos exponer las siguientes:

a) Planes de Lucha contra el Fraude Fiscal de la Comunidad Foral de Navarra. Como ya comentamos en el apartado anterior, podemos considerar que la Comunidad Foral de Navarra ha introducido elementos en sus políticas que nos permiten calificarlas como ejemplares, pues ha recogido la obligación por parte del Gobierno de Navarra de elaborar y presentar ante el Parlamento un plan o estrategia cuatrienal de lucha contra el fraude fiscal, a través de la disposición Adicional 6. ${ }^{a}$ de la Ley Foral 14/2013, de 17 de abril, de Medidas contra el fraude fiscal ${ }^{115}$. En este Plan de lucha contra el fraude fiscal (en

info en https://bit.ly/2Nw62JE). Tal vez el Gobierno de Canarias podría aprender de esta iniciativa puesta en marcha en Uruguay para educar a la población más joven en el ámbito fiscal, a través de los videojuegos, en lugar de esta iniciativa.

${ }_{112}$ Más información en http://www.dgi.gub.uy/educa.

113 OCED: op. cit., pp. 69-74.

114 Más información en http://educa.hacienda.go.cr:8080/costarica_prod/.

115 BON núm. 80, de 29 de abril de 2013. 
adelante, PLCFF), que ya se venía realizando desde el año 2008 y que se ha promulgado en tres ocasiones, con versiones distintas (2008-2012, 20142017 y 2016-2019) $)^{116}$, es habitual incorporar, además de los programas de cumplimento voluntario a los que ya nos hemos referido, un apartado específico sobre educación cívico-tributaria o educación fiscal, por considerarlo «uno de los instrumentos que mayor utilidad puede ofrecer para prevenir el fraude fiscal». Dicho apartado introduce también medidas específicas encaminadas a la introducción de la misma en la sociedad, a través de la educación en valores y la formación e información a la ciudadanía, como pueden ser -en el PLCFF 2016-2019- la introducción en los planes educativos de materias relacionadas con la administración presupuestaria y tributaria, la mejora de la percepción por el público del esfuerzo tributario o la mejora en la producción y difusión de las estadísticas tributarias, entre otras.

b) Contenidos de educación tributaria y conciencia fiscal en los centros de enseñanza del País Vasco. También podemos referirnos a otra iniciativa, esta vez dirigida a los centros educativos, que nace del Departamento de Educación del Gobierno Vasco, a raíz de una sugerencia del Departamento de Hacienda y Finanzas en el marco de las políticas contra el fraude. Esta medida consiste en la incorporación desde el curso 2015-2016 al currículo de las asignaturas de Valores Sociales y Cívicos en Primaria y Valores Éticos en Secundaria, de contenidos relativos a la educación tributaria y a la conciencia fiscal, en los que se explicaría la importancia de los impuestos para el mantenimiento de los servicios públicos y el Estado de Bienestar ${ }^{117}$. Esta experiencia nos demuestra que es fundamental incluir, como ya hemos visto en las propuestas de buenas prácticas de otros países, en el marco de los centros educativos programas de educación cívico-tributaria, para sensibilizar a la población más joven sobre estos asuntos, con especial énfasis en su conciencia fiscal.

En cuanto a la Comunidad Autónoma de Canarias, no tenemos material ni datos suficientes que nos permitan pensar que, como en el País Vasco o Navarra, se haya implantado algún programa específico -más allá de medidas puntuales o meras estrategias comunicativas - relativo a la educación cívico-tributaria de forma análoga al PECT impulsado por la Agencia Estatal de Administración Tributaria, por lo que podemos considerar, como reza el título del presente trabajo, que, por ahora, es una asignatura pendiente también para nuestra Comunidad Autónoma. Ante esta realidad, esperamos, por el bien de nuestro sistema tributario, que esto sea así por poco tiempo, pues resulta ciertamente recomendable, especialmente en nuestra Comunidad Autónoma, en la que contamos con un sistema fiscal especial

116 Podemos encontrar el más reciente de ellos, el Plan de lucha contra el fraude fiscal 20162019, aún vigente y sobre el que nos basamos para exponer esta propuesta de buenas prácticas, en el siguiente enlace web: https://bit.ly/2Qb4xix.

117 Noticia publicada en la agencia Europa Press el 16 de agosto de 2015. Disponible en el siguiente enlace: https://bit.ly/2wXLb7s. 
y particular respecto al resto del Estado, la implantación de una estrategia de educación cívico-tributaria específica para la ciudadanía canaria.

Sin duda, podríamos señalar más propuestas de buenas prácticas de otros territorios de dentro y fuera de España sobre la implantación de la educación cívico-tributaria en sus sociedades, lo cual nos ocuparía extensas páginas, pero únicamente pretendíamos hacer constar en este trabajo un catálogo de algunas propuestas que evidenciarían que disponemos a nuestro alcance de los recursos y las referencias suficientes para acometer la urgente y necesaria implantación de la educación cívico-tributaria en nuestro país para acabar, entre otras cosas, con la dialéctica de las presunciones o la posición del Estado como agente denostador de lo tributario, y que, si aún no hemos emprendido con éxito dicha tarea, es por la falta de -en palabras de Sainz de Bujanda- «un sincero y decidido empeño» por parte del Estado.

\section{CONCLUSIONES}

A la vista de lo que hemos planteado a lo largo de esta investigación podemos afirmar que la educación cívico-tributaria es, como reza el título de este trabajo, por un lado, una asignatura pendiente $y$, por otro, un instrumento imprescindible en la lucha contra el fraude fiscal.

Es una asignatura pendiente porque, a pesar de que la Administración Tributaria ha intentado implantar un Programa de Educación Cívico-Tributaria, éste ha tenido escasos resultados, debido a la falta de compromiso y apoyo financiero e institucional. En consecuencia, los problemas que aquejaban a nuestro sistema tributario en la década de los sesenta del siglo pasado, y que tan lúcidamente destacó el profesor Sainz de Bujanda, siguen vigentes en la España del siglo xxi, lo cual se demuestra con la pervivencia, entre otras cuestiones, de la dialéctica de las presunciones Estado ladrón o Fisco usurpador y contribuyente defraudador, prejuicios que inciden sobre los comportamientos sociales y generan un clima de desconfianza entre los contribuyentes y la Administración Tributaria, que provoca un aumento imparable de la mentira y la injusticia fiscales. Ha quedado más que patente, como ya nos advirtió el profesor, que éste y el resto de los problemas que aquejan a la educación tributaria en España seguirán estando vigentes indefinidamente hasta que el Estado demuestre con decisiones políticas su sincero compromiso de acabar con ellos, a través de la educación cívico-tributaria de la población.

Con el paso del tiempo hemos detectado, además del mecanismo de las presunciones que destacara Sainz de Bujanda hace más de medio siglo, una nueva actitud por parte del Estado que no resulta para nada favorecedora de la educación cívico-tributaria: la que he denominado paradoja del Estado denostador de lo tributario; expresión con la que, entiendo, cabe referirse a que cada vez con más frecuencia los discursos políticos - casi sin excepción- reniegan de la razón de ser de los tributos como un instrumento de justicia social, mostrando una peligrosa tendencia a rechazar su empleo preferente para financiar el gasto público, como ha establecido el legislador constitucional. Si el Estado denuesta lo tributario, rehúye de la materia impositiva y únicamente se refiere a esta cuestión en el marco de cam- 
pañas de marketing relativas al alivio fiscal de los contribuyentes, no debe extrañarnos el aumento incesante del fraude fiscal en nuestro país. En suma, una actitud denostadora de lo tributario por parte del Estado fomenta las conductas defraudadoras de la ciudadanía.

La educación cívico-tributaria se presenta también como un instrumento necesario, más aún, imprescindible, para la lucha contra el fraude fiscal; Sainz de Bujanda nos decía incluso que, de entre todos los posibles, es el más potente y eficaz. La finalidad más imperiosa a la hora de combatir el fraude de los contribuyentes en el cumplimiento de sus obligaciones tributarias no debería pasar exclusivamente por obtener la recaudación que éstos pretenden defraudar, sino por intensificar la conciencia fiscal o responsabilidad moral de los contribuyentes, facilitando así una mejora de éstos a través precisamente de la educación cívico-tributaria. Es por ello por lo que los métodos coercitivos languidecen y resultan ineficaces en la lucha contra el fraude fiscal, lo cual demuestra la necesidad de que la Administración opte por incentivar, como ya se está haciendo en algunas Comunidades Autónomas, el cumplimiento voluntario de las obligaciones tributarias por parte de los contribuyentes, creando una relación institucional cooperativa, tal como recomienda la OCDE. Además, debemos aclarar que la educación cívico-tributaria no solo revertiría en el cumplimiento de los contribuyentes de sus obligaciones fiscales, sino que también provocaría el rechazo y la resistencia consciente de éstos ante posibles actitudes injustas por parte de la Administración; siendo ambas cuestiones las que nos convertirían en una mejor sociedad.

Dicho esto, una vez que hemos concluido que es crucial -y un deber del Estado-para la colectividad la implantación de políticas encaminadas a la mejora de la educación cívico tributaria de la sociedad, debemos determinar cuál es el modelo para ello, para lo que contamos con un enorme catálogo de numerosas propuestas de dentro y fuera de España, que han puesto en marcha con éxito la educación cívico-tributaria en sus sociedades, poniendo especial énfasis en la población más joven, a través de los centros educativos, así como experiencias novedosas, como los programas de cumplimiento tributario voluntario y cooperativo. No nos corresponde a nosotros determinar cómo se debería implantar esta pretendida educación fiscal, pero sí alertar de que determinadas actitudes y decisiones de los Gobiernos - de dudosa legalidad- dificultan dicha imperiosa tarea, como pueden ser la confusión de la propaganda con la información, la existencia de normas jurídicas oscuras, imprecisas e ininteligibles o la cuestionable gestión de los recursos públicos por parte de la Administración, con un déficit notable de honestidad.

Por último, pero no menos importante, es imprescindible destacar que la introducción decidida de la educación cívico-tributaria en nuestra sociedad reportaría la mejora del principio de justicia -y solidaridad- que, no solo irradia sobre nuestro sistema tributario, sino que también es, según nuestra Carta Magna, un valor superior de nuestro ordenamiento jurídico.

Y, precisamente en este sentido, volvemos a sostener como función del jurista la defensa, sin sostener posición neutral alguna, de los valores que encarna el Derecho; una enseñanza que Sainz de Bujanda nos legó y que, sobre todo en estos tiempos, debemos seguir protegiendo como un símbolo que evidencia también los 
beneficios de una educación fiscal, capaz de convertir nuestra sociedad en una más libre, más igualitaria, más justa y más plural.

ReCIBIDO: agosto de 2020; ACEPTADO: noviembre de 2020 
